\title{
Guía de Práctica Clínica Nacional para el tratamiento del cáncer de pulmón de células no pequeñas en estadios tempranos, localmente avanzados y metastásicos
}

Feliciano Barrón-Barrón ${ }^{1}$, Enrique Guzmán-de Alba², Jorge Alatorre-Alexander ${ }^{2}$, Fernando Aldaco-Sarvide ${ }^{3}$, Yolanda Bautista-Aragón ${ }^{4}$, Mónica Blake-Cerda ${ }^{5}$, Yazmín Carolina Blanco-Vázquez ${ }^{5}$, Saúl Campos-Gómez ${ }^{6}$, José Francisco Corona-Cruz ${ }^{1}$, Marco Antonio Íñiguez-Garcia ${ }^{2}$, Francisco Javier Lozano-Ruiz', Federico Maldonado-Magos ${ }^{1}$, Dolores de la Mata-Moya ${ }^{5}$, Luis Manuel Martínez-Barrera ${ }^{2}$, Rubí Ramos-Prudencio ${ }^{8}$, Jerónimo Rodríguez-Cid², Samuel Rivera-Rivera4, Raul Rogelio Trejo-Rosales ${ }^{4}$, Marco Rodrigo AguilarOrtíz ${ }^{9}$, Horacio Astudillo-de la Vega ${ }^{4}$, Luis Javier Barajas-Figueroa ${ }^{10}$, Nimbe Barroso-Quiroga ${ }^{11}$, Andrés Blanco-Salazar ${ }^{6}$, Graciano Castillo-Ortega ${ }^{12}$, Luis Manuel Domínguez-Parra ${ }^{13}$, María Isabel EnriquezAceves ${ }^{12}$, Armando Fernández-Orozco ${ }^{4}$, Marco Antonio Figueroa-Morales ${ }^{14}$, León Green-Schneewiss ${ }^{5}$, Jorge Alejandro González-Garay ${ }^{9}$, Rogelio González Ramírez-Benfield ${ }^{15}$, Alberto Guadarrama-Orozco ${ }^{4}$, Jorge Guerrero-Ixtlahuac ${ }^{1}$, David Hernández-Barajas ${ }^{16}$, Raymundo Hernández-Montes de Oca ${ }^{5}$, Javier Kelly-García ${ }^{17}$, Miguel Lázaro-León ${ }^{18}$, Fernando Silva-Bravo ${ }^{19}$, Jóse Luis Téllez-Becerra², Eleazar Omar Macedo-Pérez ${ }^{1}$, Gibert Maza-Ramos ${ }^{6,9}$, José Luis Mayorga-Butrón ${ }^{9,20}$, Bertha Beatriz MontañoVelázquez ${ }^{5,20}$, Karina Murillo-Medina ${ }^{21}$, Salvador Narváez-Fernández ${ }^{12}$, Francisco Javier Ochoa-Carrillo ${ }^{1}$, Guillermo Olivares-Beltrán ${ }^{5}$, Carlos Olivares-Torres ${ }^{16}$, Mario Ponce de León-Castillo ${ }^{17}$, Mario Alberto PonceViveros $^{4}$, Jaime Ernesto Rubio-Gutiérrez ${ }^{17}$, Julia Angelina Sáenz-Frías ${ }^{14}$, Jorge Alberto Silva-Vivas ${ }^{17}$, Patricio Santillán-Doherty ${ }^{8}$, Juan José Soto-Ávila ${ }^{17}$, Vinicio Toledo-Buenrostro ${ }^{7}$, Benito Vargas-Abrego ${ }^{18}$, Liliana Velasco-Hidalgo ${ }^{9}$, Marta Margarita Zapata-Tarres ${ }^{9}$ y Óscar G. Arrieta-Rodríguez ${ }^{1 *}$

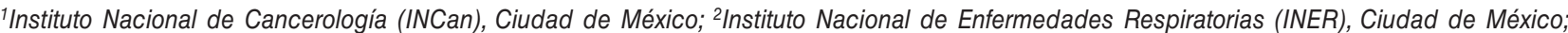
${ }^{3}$ Centro Médico Nacional 20 de Noviembre, ISSSTE, Ciudad de México; ${ }^{4}$ Hospital de Oncología, Centro Médico Nacional Siglo XXI, IMSS, Ciudad de México; ${ }^{5}$ Centro de Cáncer ABC, Centro Médico ABC, Ciudad de México; ${ }^{6}$ Centro Oncológico Estatal, Instituto de Seguridad Social del Estado de México y Municipios, Toluca, Estado de México; ${ }^{7}$ Centro Oncológico Médica Sur, Ciudad de México; ${ }^{8}$ Instituto Nacional de Ciencias Médicas y de Nutrición Dr. Salvador Zubirán, SSA, Ciudad de México; ${ }^{9}$ Instituto Nacional de Pediatría, Ciudad de México; ${ }^{10}$ Grupo Ángeles Ciudad de México, Ciudad de México; ${ }^{11}$ Hospital Universitario Dr. Ángel Leaño, Nuevo México, Jalisco; ${ }^{12}$ Instituto Mexicano del Seguro Social, León, Guanajuato; ${ }^{13}$ Star Médica,Tijuana, Baja California; ${ }^{14}$ Centro Médico del Noreste UMA 25 IMSS, Monterrey, Nuevo León; ${ }^{15}$ Hospital Civil de Guadalajara, Jalisco; ${ }^{16} \mathrm{Hospital}$ General del Estado Hermosillo Sonora; ${ }^{17}$ Instituto Jaliciense de Cancerología, Guadalajara, Jalisco; ${ }^{18} \mathrm{Hospital}$ General de México Dr. Eduardo Liceaga, Ciudad de México; ${ }^{19}$ IMSS, Puebla; ${ }^{20}$ Programa de Maestría y Doctorado en Ciencias Médicas, Unidad de Posgrado, Facultad de Medicina, UNAM, Ciudad de México; ${ }^{21}$ Hospital Regional General Zaragoza, ISSSTE, Ciudad de México. México
\end{abstract}

\section{Resumen}

Introducción: El cáncer de pulmón es una de las principales causas de mortalidad alrededor del mundo. Su historia natural, con la manifestación de síntomas en estadios avanzados y el retraso en el diagnóstico, hacen que una gran proporción de pacientes se diagnostiquen en estadios tardíos de la enfermedad, lo que hace muy complicado su tratamiento exitoso. De esto deriva la importancia de dar origen a recomendaciones basadas en evidencia para soportar la toma de decisiones clínicas por parte de los grupos interdisciplinarios que se encargan del tratamiento de este padecimiento. Objetivos: Esta Guía de Práctica Clínica (GPC) contiene recomendaciones clínicas desarrolladas de forma sistematizada para asistir la toma de decisiones de médicos

\section{Correspondencia:}

*Oscar G. Arrieta Rodríguez

E-mail: oscararrietaincan@gmail.com BY-NC-ND (http://creativecommons.org/licenses/by-nc-nd/4.0/).
Fecha de recepción: 06-11-2018

Fecha de aceptación: 13-12-2018

DOI: $10.24875 /$ j.gamo.M18000162
Disponible en internet: 20-03-2019

Gac Mex Oncol. 2018;17:201-232

www.gamo-smeo.com 
especialistas, pacientes, cuidadores de pacientes y elaboradores de políticas públicas involucrados en el tratamiento de pacientes con cáncer de pulmón en estadios tempranos, localmente avanzados y metastásicos. Material y métodos: Este documento se desarrolló por parte de la Sociedad Mexicana de Oncología en colaboración con el Centro Nacional de Excelencia Tecnológica (CENETEC) en Salud por medio de la dirección de integración de GPC en cumplimiento a estándares internacionales como los descritos por el IOM (Institute of Medicine, Instituto de Medicina) de EE.UU., el NICE (National Institute for Clinical Excellence, Instituto Nacional para la Excelencia Clínica del Reino Unido), Ia SIGN (Scottish Intercollegiate Guidelines Network, Red Escocesa Intercolegiada sobre GPC), la GIN (Guideline International Network, Red Internacional de Guías) y el CENETEC de México, entre otros. En representación de la Sociedad Mexicana de Oncología se integró un Grupo de Desarrollo de la Guía (GDG) de manera interdisciplinaria, considerando oncólogos médicos, cirujanos oncólogos, cirujanos de tórax, radiooncólogos y metodólogos con experiencia en revisiones sistemáticas de la literatura y GPC. Resultados: Se consensuaron 62 preguntas clínicas que abarcaron lo establecido previamente por el GDG en el documento de alcances de la Guía. Se identificó y evaluó críticamente la evidencia científica que responde a cada una de estas preguntas clínicas antes de ser incorporadas en el cuerpo de evidencia de la Guía. El GDG acordó mediante la técnica de consenso formal de expertos Panel Delphi la redacción final de las recomendaciones clínicas. Conclusión: Esta GPC pretende proveer recomendaciones clínicas para el tratamiento de los distintos estadios de la enfermedad y que asistan en el proceso de toma de decisiones compartida. EI GDG espera que esta Guía contribuya a mejorar la calidad de la atención clínica en los pacientes con cáncer de pulmón de células no pequeñas (CPCNP).

Palabras clave: Cáncer de pulmón. Cáncer de pulmón estadios tempranos. Cáncer de pulmón localmente avanzado. Cáncer de pulmón metastásico. Guías de práctica clínica. Medicina basada en evidencia.

\section{National Clinical Practice Guideline for the treatment of non-small cell lung cancer in early, locally advanced and metastatic stages}

\section{Abstract}

Introduction: Lung cancer is one of the leading causes of mortality worldwide. Symptomatic manifestations of the disease generally occur in the advanced-stage setting, and therefore an important number of patients have advanced or metastatic disease by the time they are diagnosed. This situation contributes to a poor prognosis in the treatment of lung cancer. Evidence-based clinical recommendations are of great value to support decision-making for daily practice, and thus improving health care quality and patient outcomes. Objectives: This Clinical Practice Guideline (CPG) contains systematically developed recommendations to support clinicians, patients and patient-carers, policy makers and other stakeholders in the diagnosis and management of patients with early, advanced and metastatic stages of non-small cell lung cancer. Methodology: This document was an initiative of the Mexican Society of Oncology (SMEO) in collaboration with the Mexican Center of Clinical Excellence (CENETEC) according to international standards. Such standards included those described by the IOM (Institute of Medicine), NICE (National Institute for Clinical Excellence), SIGN (Scottish Intercollegiate Guidelines Network) and GIN (Guideline International Network). An interdisciplinary Guideline Development Group (GDG) was formed which included medical oncologists, surgical oncologists, radiation therapists, and methodologists with expertise in critical appraisal, systematic reviews and clinical practice guidelines development. Results: 62 clinical questions were agreed among members of the GDG. With the evidence identified from systematic reviews, the GDG developed clinical recommendations using a modified Delphi Panel technique. Patients' representatives validated them. Conclusions: This CPG aims to support the shared decision-making process for patients with different stages of non-small cell lung cancer. Our goal is to improve health-care quality on these patients.

Key words: Non-small lung cancer. Clinical practice guidelines. Evidence based medicine.

\section{Introducción}

El cáncer de pulmón representa un problema de salud pública y es actualmente la primera causa de muerte por cáncer en México y en el mundo'. A pesar de la gran cantidad de avances que se han registrado en las últimas décadas, solo entre el $5-16 \%$ de los pacientes logra sobrevivir cinco años ${ }^{2}$. En México se diagnostican anualmente entre 9,000-11,000 nuevos casos y la mortalidad anual se estima en 6,678 muertes en promedio $^{3}$. Un gran reto clínico es realizar el diagnóstico temprano, el cual solo se logra en aproximadamente el $10 \%$ de los pacientes, ofreciendo la posibilidad de curación. El otro $90 \%$ de los casos son diagnosticados 
en etapas más avanzadas o metastásicas de la enfermedad, para las cuales las opciones de tratamientos curativos son muy escasas, si no es que nulas ${ }^{1,4}$.

El principal factor de riesgo continúa siendo el tabaquismo, por lo cual uno de los mayores retos es lograr generar programas exitosos para la educación poblacional y la prevención del uso del tabaco ${ }^{5}$. Sin embargo, debido a las características inherentes de la enfermedad es importante que a la par de las campañas de prevención se generen estrategias para lograr el diagnóstico expedito y permitir el acceso al mejor tratamiento, lo cual es indudablemente un desafío para las autoridades de salud ${ }^{6,7}$.

En la actualidad se han logrado grandes avances en términos de conocimiento de la enfermedad y el abordaje de estos pacientes, contamos con diversas opciones terapéuticas y por primera vez tenemos la posibilidad de ofrecer terapia personalizada con base en datos sólidos de epidemiología generados en nuestra región $n^{8,9}$. Esto es de particular relevancia, especialmente cuando consideramos que durante la segunda mitad del siglo XX la terapéutica para pacientes con cáncer de pulmón se mantuvo inalterada, y consistió en el uso único o en combinación de la cirugía, radioterapia (RT) y/o quimioterapia (QT)2. El siglo XXI ha traído consigo una mayor comprensión de los mecanismos moleculares implicados en la génesis del cáncer de pulmón, y como consecuencia diversas moléculas han emergido como terapias que se dirigen a alteraciones moleculares específicas, mejorando así las tasas de respuesta y la supervivencia de ciertos subgrupos de pacientes ${ }^{10-12}$.

Tomando en cuenta estos propósitos y la gran cantidad de información que se ha generado en los últimos años, se han establecido diversas asociaciones que buscan, mediante la unión entre académicos de diversas regiones, frenar el problema actual y sugerir estrategias a futuro. Por medio de diversos congresos médicos que conjuntan la experiencia clínica, los datos epidemiológicos y los avances en ciencia básica hemos logrado establecer un grupo de expertos provenientes de decenas de instituciones que incluyen especialistas de diversas áreas para lograr una visión integral del paciente con cáncer de pulmón ${ }^{1}$. Este panel de expertos incluyó a cirujanos oncólogos, cirujanos de tórax, radiooncólogos y oncólogos médicos para generar esta Guía Nacional para el Tratamiento del Cáncer de Pulmón.

El objetivo principal de la creación de estas guías fue lograr una estrategia adecuada para nuestra región que permita incorporar el conocimiento más reciente junto con la experiencia clínica y las posibilidades económicas e institucionales con el propósito de mejorar la supervivencia de los pacientes con cáncer de pulmón, distribuyendo a lo largo del país información actualizada y concreta para el personal de salud que tiene a su cargo el cuidado de estos pacientes.

A medida que nos aventuramos a la era de la medicina personalizada ${ }^{13}$, la Guía Nacional para el Tratamiento del Cáncer de Pulmón de manera entusiasta ofrece las actualizaciones pertinentes para ofrecer a nuestros usuarios el estado del arte en esta cuestión. Sabemos que los médicos enfrentamos dos grandes retos en este tema: el acceso a la información más novedosa y pertinente y el acceso a las terapias de última generación que ofrecen beneficios en términos de eficacia y seguridad. Estamos certeros de que esta actualización logrará ayudar a los médicos a enfrentar el primer reto. Mediante este esfuerzo, los autores involucrados en este trabajo consolidamos nuestra dedicación a proporcionar información para ofrecer un cuidado integral, que impacte de manera sólida y positiva en la vida de los pacientes a quienes nos debemos.

\section{Medicina basada en evidencia y los objetivos de la Guía}

La definición actual de medicina basada en evidencia es el «uso juicioso, explícito y concienzudo de la mejor evidencia científica disponible, aunado con la mejor experiencia clínica, los valores y preferencias de los pacientes y considerando los costos para el mejor cuidado de los pacientes» ${ }^{14}$. La experiencia clínica conlleva un proceso de aprendizaje e integración del conocimiento que requiere de tiempo y que se va perfeccionando progresivamente hasta obtener las habilidades diagnósticas y terapéuticas para un mejor cuidado de los pacientes ${ }^{14-16}$. La medicina basada en evidencia, sin duda, requiere de herramientas que faciliten la incorporación de todo el conocimiento científico que va surgiendo a la toma de decisiones clínicas en nuestros pacientes ${ }^{17}$. Las revisiones sistemáticas (RS) de la literatura contienen protocolos de investigación explícitos, rigurosos y exhaustivos para identificar y evaluar de forma crítica, así como sintetizar, los estudios relevantes ${ }^{17}$. Después de casi cuatro décadas de desarrollar una metodología que persigue la disminución de sesgo en las conclusiones, las RS de la literatura se han convertido en la piedra angular de la medicina basada en evidencia ${ }^{14,17}$ (Fig. 1). 


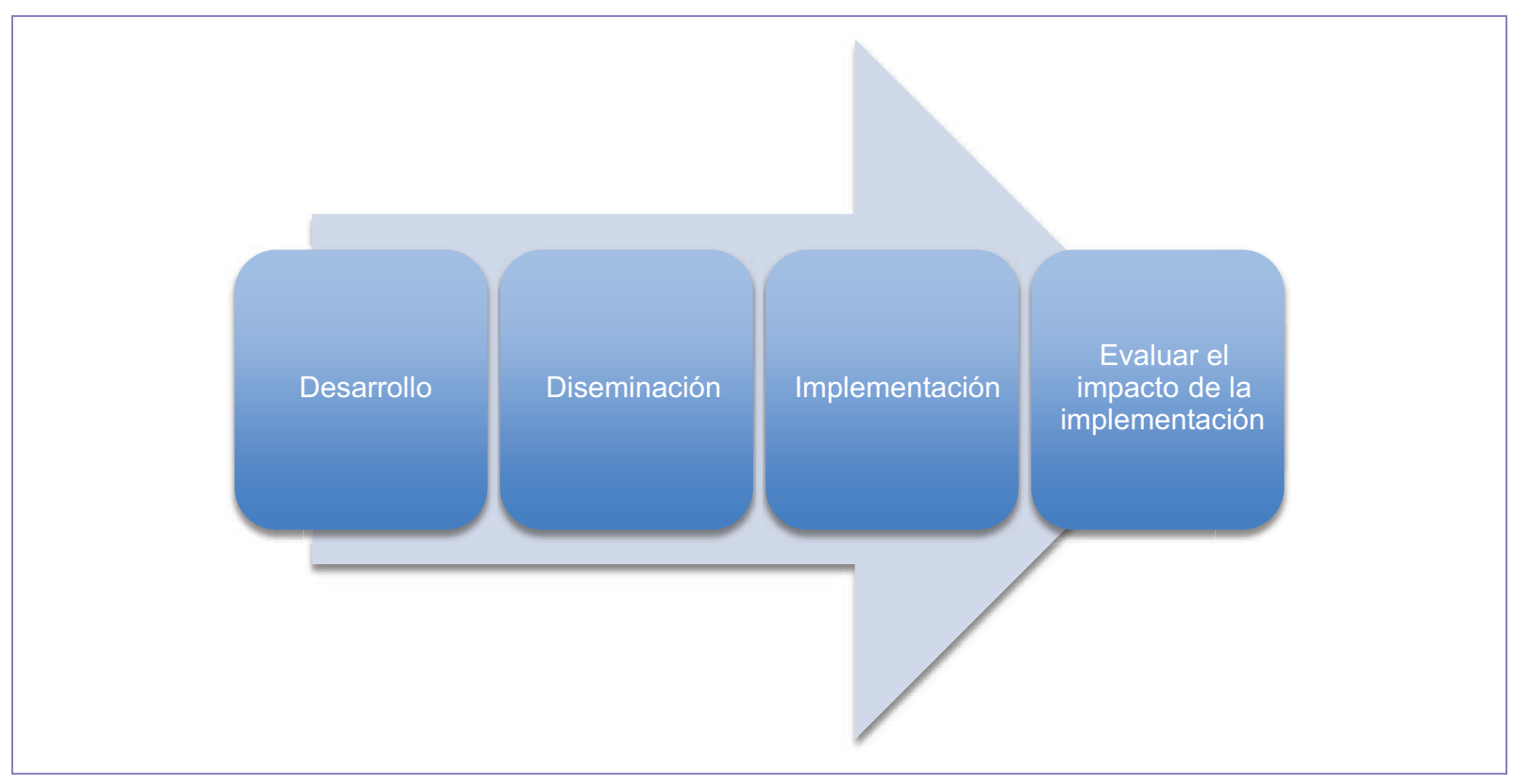

Figura 1. Ciclo de vida de las Guías de Práctica Clínica. Las etapas de desarrollo, diseminación, implementación y de evaluación del impacto de la implementación de las Guías de Práctica Clínica en los distintos escenarios clínicos constituyen su ciclo de vida (adaptado de Mayorga-Butrón, et al., 2015²7).

Al inicio de la década de 1990 se da un impulso clave a otro instrumento que se situará como pieza clave en la medicina basada en evidencia, las Guías de Práctica Clínica (GPC) basadas en la evidencia ${ }^{18-20}$. El reporte del IOM (Institute of Medicine, Instituto de Medicina) define a las GPC como «recomendaciones desarrolladas sistemáticamente para asistir a los clínicos y a los pacientes en su toma de decisiones para una mejor calidad en la atención de la salud en condiciones específicas». El objetivo primordial de las GPC es cerrar la brecha entre el conocimiento científico y la toma de decisiones por parte de profesionales de la salud y pacientes, apoyar en los procesos de educación médica, auxiliar a los desarrolladores de políticas públicas y administradores para hacer más eficiente el uso de recursos y decidir sobre las tecnologías en salud más eficientes en cuanto a costo ${ }^{21-23}$ (Fig. 2).

Las GPC requieren un protocolo bien establecido para su desarrollo. Requieren además que a la mejor evidencia disponible se le incorpore la mejor experiencia clínica, pero también los puntos de vista de los usuarios finales, entre los que se deben de contemplar pacientes y sus cuidadores, administrativos, médicos familiares, realizadores de políticas en salud y cualquier organización que se desarrolle en el campo de la atención médica ${ }^{23-25}$.

La clasificación de la evidencia científica se llevó a cabo tomando en cuenta la clasificación desarrollada por la SIGN (Scottish Intercollegiate Guidelines Network, Red Escocesa Intercolegiada sobre GPC) (Tabla 1), en ella se otorga el nivel más alto de evidencia a las RS de estudios clínicos sorteados (ECS) con muy bajo riesgo de sesgo, y así va disminuyendo la calidad de la evidencia, pasando por ECS con alto riesgo de sesgo, estudios de cohortes, casos y controles hasta llegar a los estudios no analíticos como las series de casos y los reportes de casos, y en el nivel inferior de la evidencia la opinión de los expertos ${ }^{26}$.

Los objetivos de esta GPC para el tratamiento del cáncer de pulmón se enfocaron en brindar recomendaciones basadas en evidencia para el tratamiento quirúrgico, médico y radiológico de todas las fases de la enfermedad con la intención de brindar más herramientas a los clínicos y de esta forma mejorar los desenlaces de los pacientes que padecen esta enfermedad tan prevalente en el mundo.

\section{Material y métodos}

\section{Grupo de Desarrollo de la Guía}

El Grupo de Desarrollo de la Guía (GDG) tiene carácter interdisciplinario y está compuesto por expertos clínicos en oncología médica, cirugía oncológica y radiooncología representantes de la Sociedad Mexicana de Oncología. También se incluyeron expertos 


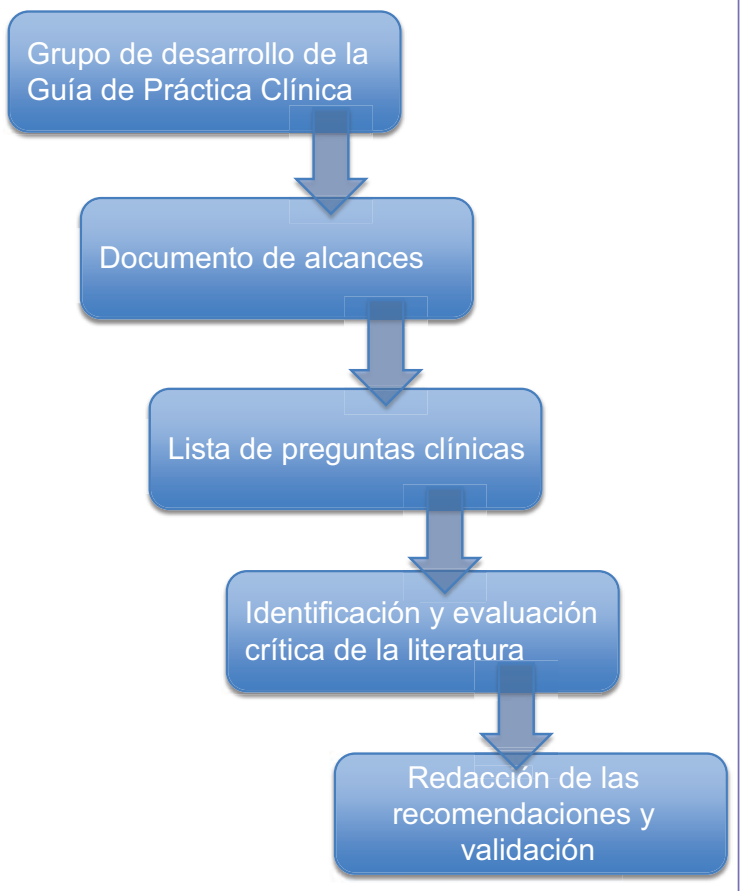

Figura 2. Flujograma general para el desarrollo de una Guía de Práctica Clínica.

metodológicos con experiencia en el desarrollo de RS de la literatura y GPC. Un grupo base (core group) se reunió en diversas ocasiones para definir el modo de trabajo, los tiempos y la distribución de las responsabilidades, así como los aspectos importantes en la definición de alcances generales de la GPC y la lista de preguntas clínicas estructuradas.

\section{Definición de alcances}

El GDG llevó a cabo la definición de los alcances generales de la GPC y se acordaron las características de la población incluida a tratar, así como también las de la población que no se incluirá en el documento. El documento de alcances provee el marco general en el cual la GPC se va a desarrollar. Describe brevemente los aspectos generales de la enfermedad y define los aspectos clínicos que la GPC va a cubrir, así como los aspectos que no serán cubiertos por esta. De igual forma, el documento de alcances describe a la audiencia blanco que se considera de interés para la GPC y a la cual se dirigen las recomendaciones clínicas (Anexo A).

Los aspectos más importantes del documento de alcances se enumeran a continuación:

- Las características de la población que se incluye.

- La definición de la población que no cubre la GPC.
- El escenario o escenarios clínicos en los cuales se planea que las recomendaciones de la GPC serán implementadas.

- Los diferentes tipos de aspectos clínicos que se evalúan en la GPC y en los cuales se contemplan pruebas diagnósticas, intervenciones médicas e intervenciones quirúrgicas, entre otros.

- Información específica para los usuarios.

- Los desenlaces clínicos que serán considerados para evaluar las distintas intervenciones terapéuticas y diagnósticas.

- Los aspectos en los cuales la GPC se espera que contribuirá al tratamiento de la enfermedad.

\section{Preguntas clínicas estructuradas}

Una vez que se acordó el contenido del documento de alcances, el GDG prosiguió a desarrollar la lista de preguntas clínicas estructuradas. El objetivo de esta fase fue el de elaborar el listado completo de preguntas clínicas que desarrollasen el tema que aborda la guía. La respuesta a estas preguntas originará recomendaciones para los usuarios de la GPC. Se aseguró que las preguntas clínicas abordaran brechas en el conocimiento y temas clínicos relevantes de acuerdo con los miembros del GDG. Todos los problemas clínicos definidos en el alcance de la guía se vieron reflejados en esta etapa mediante las preguntas clínicas, para garantizar así que la GPC se desarrollara conforme a los objetivos planteados. Por lo tanto, la intención fue que las preguntas clínicas fueran claras, precisas y específicas, para facilitar la búsqueda y la revisión de la evidencia científica y así evitar recomendaciones poco ajustadas a los problemas clínicos que plantea la GPC (Anexo B).

El listado de preguntas contempló la población, las intervenciones y los comparadores estipulados en el documento de alcances. El GDG evitó introducir aspectos nuevos que no estuvieran incluidos en el alcance de la guía.

Se consideró el esquema población-intervención-comparador-desenlace (PICO) y de acuerdo con este se tomaron en cuenta los siguientes componentes: - Paciente: grupos de edad, estadio de la enfermedad, comorbilidad, etc.

- Intervención: intervención, factor pronóstico, agente etiológico, prueba diagnóstica, tratamiento habitual o placebo, ausencia de un factor de riesgo, ausencia de agente etiológico, patrón oro o de referencia de una prueba diagnóstica, etc. 
Tabla 1. Clasificación del nivel de la evidencia y de los grados de recomendación de acuerdo a SIGN (2001)

\section{Niveles de evidencia}

1++ Revisiones sistemáticas con metaanálisis de ECS, o ECS con muy bajo riesgo de sesgo

$1+$ Revisiones sistemáticas de la siteratura con metaanálisis de ECS, o ECS con bajo riesgo de sesgo

1- Revisiones sistemáticas de la literatura con metaanálisis de ECS, o ECS con alto riesgo de sesgo

2++ Revisiones sistemáticas de alta calidad de estudios de cohortes o casos y controles con muy bajo riesgo de sesgo, de variable confusoras, 0 una alta probabilidad de que la asociación sea causal

$2+$ Estudios de casos y controles bien diseñados con un riesgo bajo de sesgo, de variable confusoras, 0 una probabilidad moderada de que la asociación sea causal

2- Estudios de casos y controles con un riesgo alto de sesgo, de variable confusoras, o riesgo significativo de que la asociación no sea causal

3 Estudios no analíticos (p. ej., series de casos, reportes de casos 4 Opinión de expertos

\section{Grados de recomendación}

A Al menos una revisión sistemática con metaanálisis, o un ECS clasificado como $1++$ y que sea directamente aplicable a la población o una revisión sistemática de ECS o evidencia que consistiera en estudios clasificados como $1+$ aplicables directamente a la población objetivo y que demuestren resultados consistentes

B Evidencia que incluya estudios clasificados como $2++$ y que sean directamente aplicables a la población objetivo y que demuestren resultados consistentes o evidencia extrapolada de estudios clasificados como 1++ $01+$

C Evidencia que incluye estudios clasificados como $2+$ y que sean directamente aplicables a la población objetivo y que demuestren resultados consistentes 0 evidencia extrapolada de estudios clasificados como 2++

D Evidencia nivel 3 o 4 o evidencia extrapolada y clasificada como $2+$

ECS: estudios clínicos sorteados; SIGN: Scottish Intercollegiate Guidelines Network Adaptada de Harbour, et al., 200126.

- Comparación: se refiere a la alternativa a la intervención en estudio, como tratamiento habitual o placebo, ausencia de un factor de riesgo, ausencia de agente etiológico, patrón oro o de referencia de una prueba diagnóstica, etc.

- Desenlaces (outcomes): variables de resultado clínicamente importantes en el caso de estudios sobre eficacia, pronóstico o etiología, y estimadores de rendimiento o validez.

\section{Búsqueda exhaustiva de la evidencia científica}

La evidencia fue identificada siguiendo algoritmos y estrategias validadas internacionalmente. Se identificaron y emplearon términos MeSH (Medical Subject Headings) para de esta forma ensamblar una estrategia de búsqueda sensible y específica, además de explícita para que sea reproducible en un futuro ${ }^{5}$. De acuerdo a la naturaleza de la pregunta clínica a responder, se estableció el tipo de estudio que fuera más fiable para contestarla y partiendo de ahí, otros tipos de estudio que pudieran responderla aunque con menos confianza en los resultados, siguiendo los modelos de clasificación de la evidencia. Entre estos criterios se consideraron las variables de desenlaces importantes para clínicos y pacientes, así como seleccionar el diseño de estudio más adecuado en función de la pregunta que se debe responder (Anexo C). La búsqueda se llevó a cabo a partir de las preguntas clínicas estructuradas. La revisión bibliográfica preliminar incluyó la localización de GPC relevantes que ya existian sobre el mismo tema. Esto permitió facilitar el ensamblaje del documento de alcances y la identificación de preguntas clínicas relevantes sobre el tema. Además nos ayudó en la identificación, la evaluación y la síntesis de la evidencia científica.

Las RS juegan un papel crucial en el proceso de elaboración de una GPC. Los estándares internacionales actuales proponen la utilización de las RS como las herramientas indispensables para la localización y selección de la evidencia científica que alimente las recomendaciones clínicas. Dependiendo del tipo de pregunta clínica será el tipo más adecuado de estudio clínico para responderla, para de ahí formar una conclusión y formular recomendaciones clínicas (Anexo C).

Una vez que los elementos de la búsqueda y selección fueron claramente definidos, se seleccionaron las bases de datos en función del tipo de publicación que se quiere buscar y el tema objeto de cada pregunta clínica. Para el resto de las publicaciones (RS o estudios originales), las bases de datos bibliográficas son las herramientas idóneas para recuperar información, al agrupar conjuntos de referencias de documentos almacenadas electrónicamente y que se pueden buscar y seleccionar de manera interactiva mediante un lenguaje de consulta o interrogación.

Las bases de datos que recopilan GPC fueron consultadas usando los términos MeSH. Las distintas bases de datos que fueron consultadas para localizar las distintas GPC publicadas y relevantes para nuestra GPC se enumeran a continuación: 
Tabla 2. Herramientas de evaluación crítica de la literatura

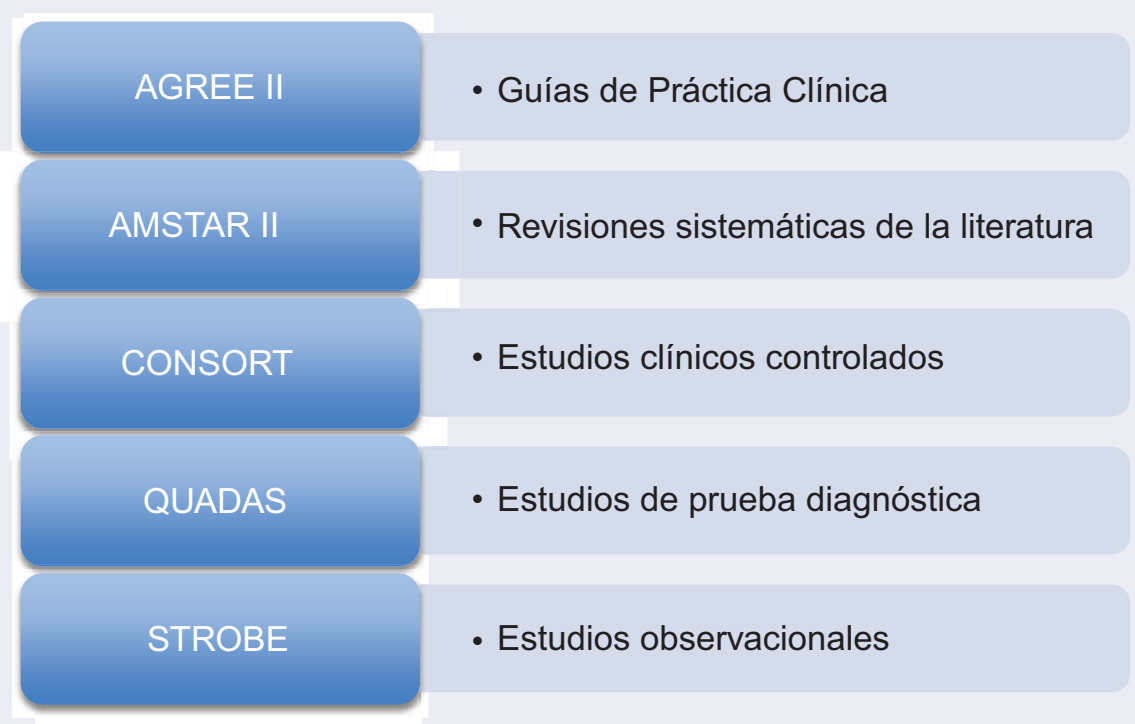

En el caso de las GPC se empleó la herramienta AGREE II (The Appraisal of Guidelines for Research \& Evaluation), para las revisiones sistemáticas de la literatura se empleó la herramienta AMSTAR II (Assessing the Methodological quality of Systematic Reviews), CONSORT (Consolidated Standards of Reporting Trials) son directrices de reporte para estudios clínicos controlados, QUADAS (Quality Assessment of Diagnostic Accuracy Studies) para estudios de prueba diagnóstica y STROBE (Strengthening the Reporting of Observational Studies in Epidemiology) para estudios observacionales.

Adaptado de: Enhancing the Quality and Transparency Of health Research [Internet]. UK EQUATOR Centre [fecha de publicación o actualización]. Disponible en: http:// www.equator-network.org

Tabla 3. Escala de Likert empleada durante la conducción del Panel Delphi Modificado

\begin{tabular}{|c|c|c|c|c|c|c|c|c|}
\hline 1 & 2 & 3 & 4 & 5 & 6 & 7 & 8 & 9 \\
\hline $\begin{array}{l}\text { Totalmente } \\
\text { en } \\
\text { desacuerdo }\end{array}$ & $\begin{array}{l}\text { Fuertemente } \\
\text { en } \\
\text { desacuerdo }\end{array}$ & Desacuerdo & $\begin{array}{l}\text { Ligeramente } \\
\text { en } \\
\text { desacuerdo }\end{array}$ & Indiferente & $\begin{array}{l}\text { Ligeramente } \\
\text { de acuerdo }\end{array}$ & $\begin{array}{l}\mathrm{De} \\
\text { acuerdo }\end{array}$ & $\begin{array}{l}\text { Fuertemente } \\
\text { de acuerdo }\end{array}$ & $\begin{array}{l}\text { Totalmente } \\
\text { de } \\
\text { acuerdo }\end{array}$ \\
\hline \multicolumn{9}{|c|}{ Incluya su respuesta con una $X$} \\
\hline $\begin{array}{l}\text { Argumente } \\
\text { su respuesta } \\
\text { con base en } \\
\text { su } \\
\text { experiencia } \\
\text { clínica y los } \\
\text { valores y } \\
\text { preferencias } \\
\text { de sus } \\
\text { pacientes. }\end{array}$ & & & & & & & & \\
\hline
\end{tabular}

Es obligatorio incluir un argumento en cada respuesta, no importando su calificación numérica

- Organismos recopiladores. El más completo es el NGC (National Guideline Clearinghouse, Centro Nacional de Guías de EE.UU.), de cobertura internacional, perteneciente a la AHRQ (Agency for Health Research and Quality, Agencia para la investigación y la calidad en salud). En el Reino Unido destaca el NeLH (Guidelines Finder National Electronic Library for Health, Localizador de Guías de la Biblioteca Electrónica Nacional de Salud del Reino Unido). El catálogo de guías realizadas en España se recoge en Guía salud. La base de datos TripDatabase es un motor de búsqueda útil que ofrece una idea rápida del volumen de GPC existentes. Se consultaron también las bases de datos de las principales sociedades y academias del área de especialidad internacionales en búsqueda de GPC publicadas.

- Organismos elaboradores. El NICE, el SIGN, el ICSI (Institute for Clinical System Improvement, Instituto 


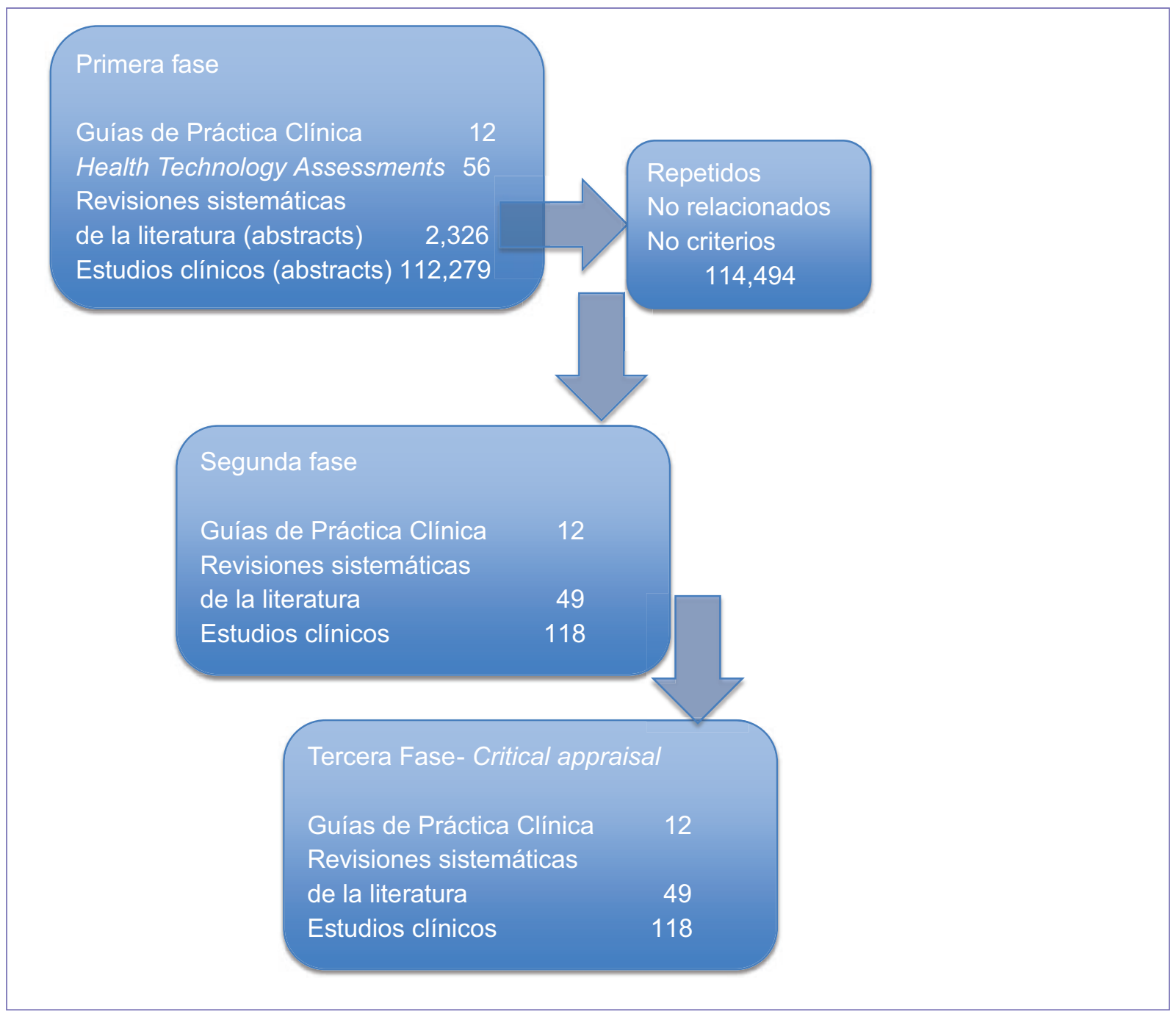

Figura 3. Flujograma del cuerpo de evidencia científica (flujograma de revisión de la literatura).

para la Mejora de los Sistemas Clínicos, en EE.UU.), el Consejo Nacional Australiano de Salud e Investigación Médica (National Health and Medical Research Council de Australia) o el NZGG (New Zealand Guidelines Group, Grupo sobre Guías de Nueva Zelanda).

- Centros de metodología. Destacan por su interés el GIN, la colaboración AGREE (The Appraisal of Guidelines for Research \& Evaluation) y el Grading of Recommendations, Assessment, Development and Evaluations (GRADE) Working Group como grupo de trabajo que desarrolla el sistema emergente GRADE: bases de datos generales. En bases como MEDLINE se indexan también GPC y existen filtros que se pueden aplicar en las búsquedas. No obstante, no es la forma más eficiente de localizarlas.

Para la búsqueda exhaustiva de RS se ensamblaron distintas estrategias de búsquedas y se utilizaron distintas bases de datos generales y especializadas en RS. Se emplearon estrategias de búsquedas publicadas y validadas que hayan demostrado ser sensibles y específicas, así como los términos MeSH.

Las bases de datos consultadas para identificar RS se enumeran a continuación: Cochrane Library (contiene RS de ECS de alta calidad, independientes y fiables para ser incluidas en el cuerpo de evidencia), Best practice, The Campbell Collaboration Library of Systematic Reviews, Centre for Reviews and Dissemination databases (incluye DARE [Database of Abstracts of Reviews of Effects]), Centre for Reviews and Dissemination, National Institute for Health Research (Reino Unido), Database of Promoting Health Effectiveness Reviews, The Database of Promoting Health Effectiveness Reviews (DoPHER), TripDatabase, The Evidence for Policy and practice Information and 


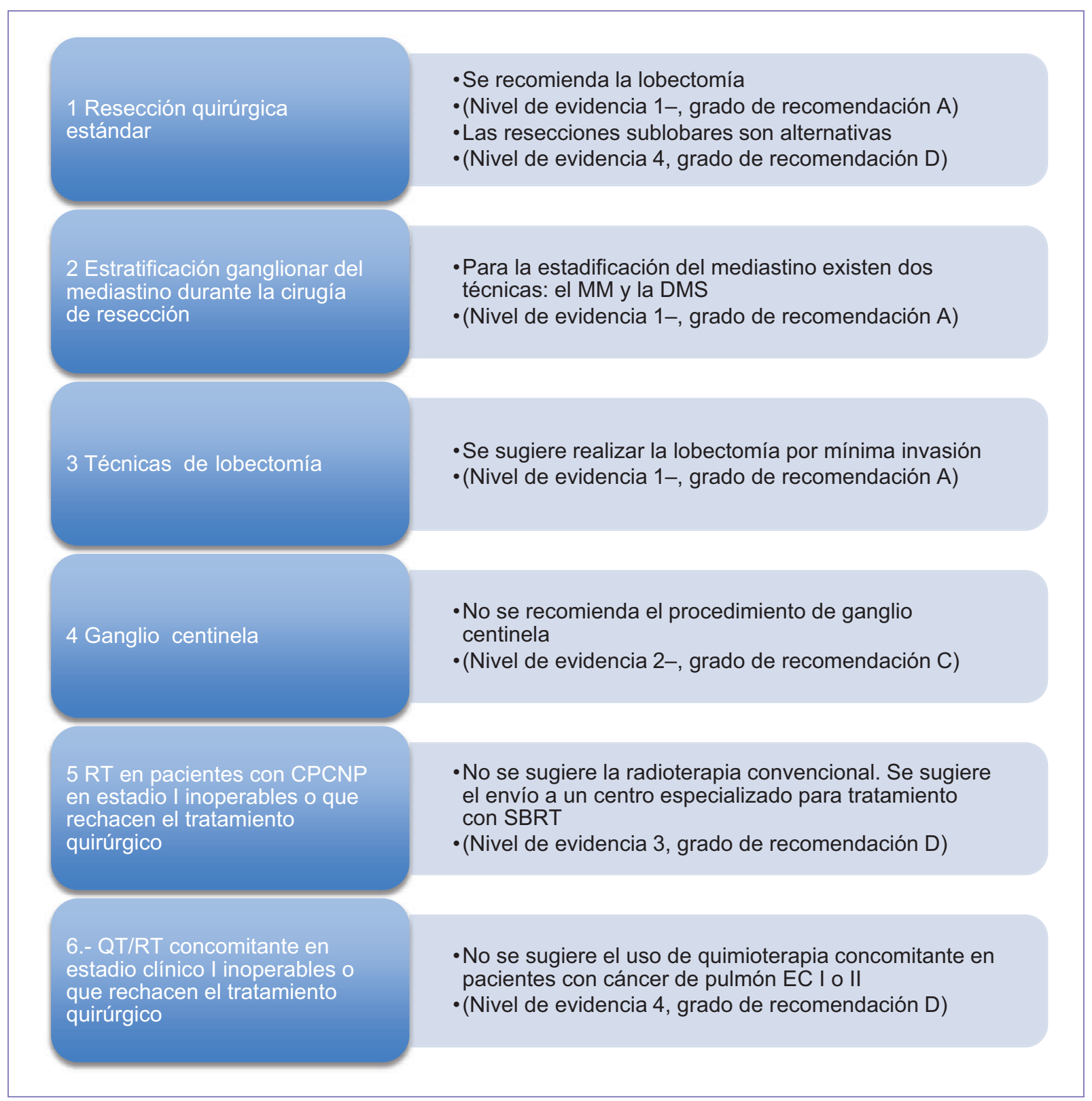

Figura 4. Síntesis de las recomendaciones clínicas para el manejo de cáncer de pulmón de células no pequeñas (CPCNP) en estadio temprano.

Cordinating Centre (EPPI-Centre), MEDLINE, PubMed (National Library of Medicine in the United States), Scopus Large international y Embase a través de OVID Technologies, Inc. NICE y el NIHR (National Institute for Health Research de Reino Unido) para identificar HTA de alta calidad.

Solamente en los casos donde las preguntas clínicas no encontraron una RS de la literatura para ser respondidas o las GPC no hubieran identificado evidencia científica de alta calidad se llevaron a cabo búsquedas exhaustivas de la literatura para identificar estudios clínicos que respondieran a esa pregunta.
Las bases de datos que se consultaron para identificar estudios clínicos publicados fueron: The Cochrane Library hasta 2017, Cochrane Central Register of ControIled Trials, Cochrane Database of Systematic Reviews, y la Database of Abstracts of Reviews of Effects (DARE) (Issue 1 2017), MEDLINE 1950-2017 (OVID), Embase 1980-2017 (OVID), Cinahl 1982-2017 (NLH Search 2.0), Health Economic and Evaluations Database (HEED) hasta 2017, Cumulative Index to Nursing and Allied Health Literature (1982 a 2017), Literatura Latinoamericana y del Caribe en Ciencias de la Salud (LILACS) (1998 a 2017), ARTEMISA (1999 a 2017) y SciELO (1999 a 2017). 


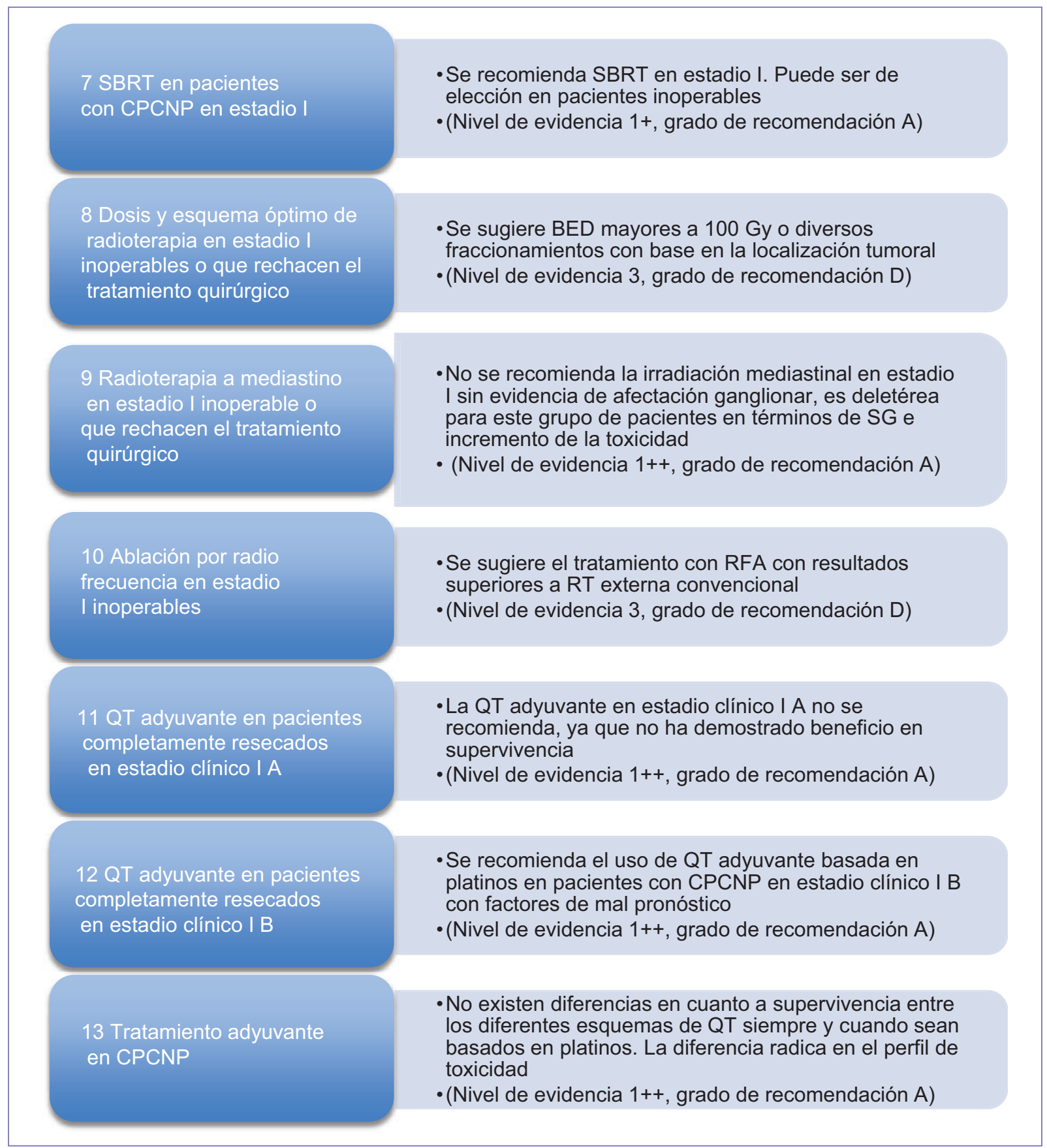

Figura 4. Síntesis de las recomendaciones clínicas para el manejo de cáncer de pulmón de células no pequeñas (CPCNP) en estadio temprano. (continuación)

\section{Evaluación de calidad y jerarquización de la evidencia}

Se emplearon herramientas diseñadas y validadas internacionalmente para evaluar la calidad de la evidencia científica considerando el tipo de documento evaluado. En el caso de las GPC se empleó la herramienta AGREE II (The Appraisal of Guidelines for
Research \& Evaluation) que fue diseñada para evaluar la calidad metodológica y variabilidad de las GPC. En el caso de las RS de la literatura se empleó la herramienta AMSTAR II (Assessing the Methodological quality of Systematic Reviews). Para el caso en el que se condujo una RS de estudios clínicos se utilizaron las siguientes herramientas validadas: directrices CONSORT (Consolidated Standards of Reporting Trials) 


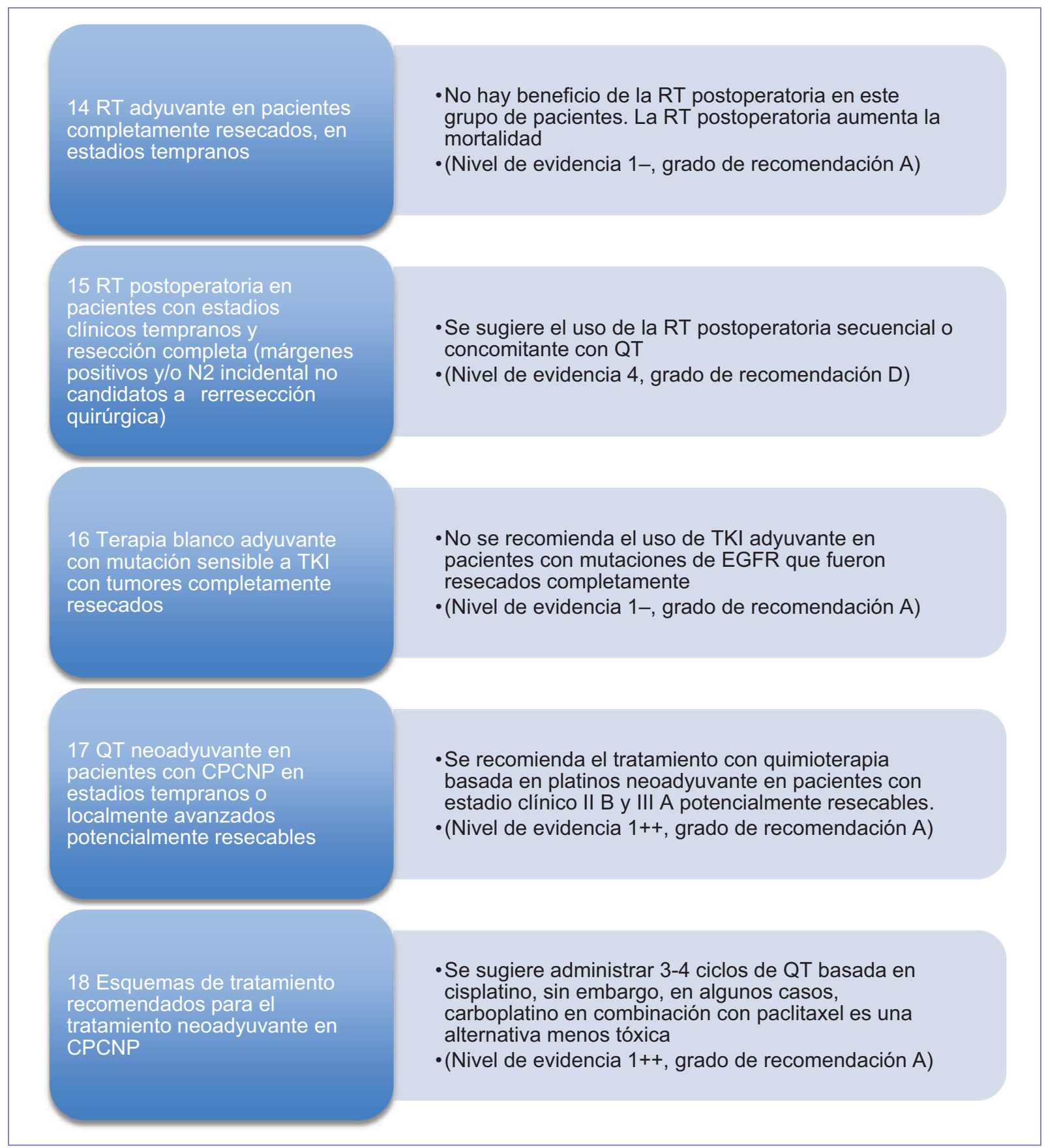

Figura 4. Síntesis de las recomendaciones clínicas para el manejo de cáncer de pulmón de células no pequeñas (CPCNP) en estadio temprano. (continuación)

para ECS, MOOSE (Metanalysis Of Observational Studies in Epidemiology), QUADAS (Quality Assessment of Diagnostic Accuracy Studies) para estudios de prueba diagnóstica, STROBE (Strengthening the Reporting of Observational Studies in Epidemiology) para estudios observacionales (Tabla 2).

Cada una de estas herramientas califican distintos rubros y usan diferentes escalas. Se emplearon de manera individual y calificado por pares, con un tercer evaluador en caso de que hubiera poca concordancia entre los revisores.

Se han publicado una gran cantidad de clasificaciones para evaluar la calidad de la evidencia, nosotros decidimos por consenso utilizar la escala desarrollada por SIGN, la cual utiliza dos atributos para evaluar la calidad de la evidencia científica (nivel de evidencia): el diseño del estudio y el riesgo de sesgo. Para la clasificación del diseño del estudio se utilizan los números del 


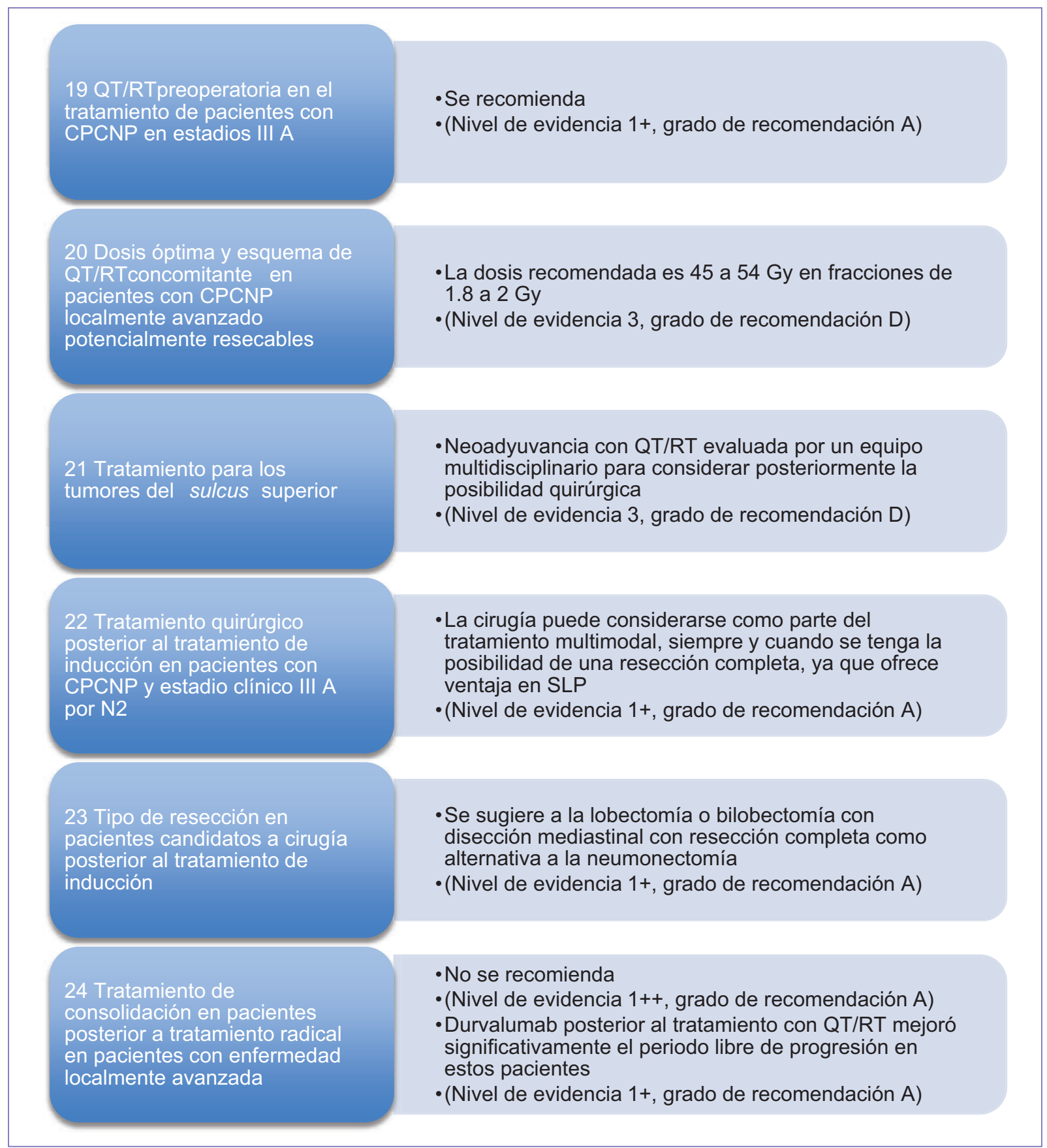

Figura 5. Síntesis de las recomendaciones clínicas para el manejo de cáncer de pulmón de células no pequeñas (CPCNP) en estadio localmente avanzado.

1 al 4 . El número 1 corresponde a ensayos clínicos o a RS de estos ensayos, y el 4 a la opinión de expertos. Para evaluar el riesgo de sesgo se utilizan signos que informan sobre el grado de cumplimiento de los criterios clave relacionados con ese potencial riesgo $(++,+\mathrm{y}-)$. De esta forma, con la ayuda de la plantilla de lectura crítica se evalúa cada estudio, ya sean estudios individuales (ECS, cohortes, etc.) o RS. Esta valoración de la calidad de la evidencia científica de los diferentes estudios disponibles para responder a las preguntas formuladas será posteriormente utilizada en la graduación de la fuerza de las recomendaciones (Tabla 1).

\section{Extracción de la evidencia y análisis}

Las GPC preferentemente tienen que incorporar RS para sostener las recomendaciones clínicas. Una vez que las RS fueron evaluadas en su calidad e 


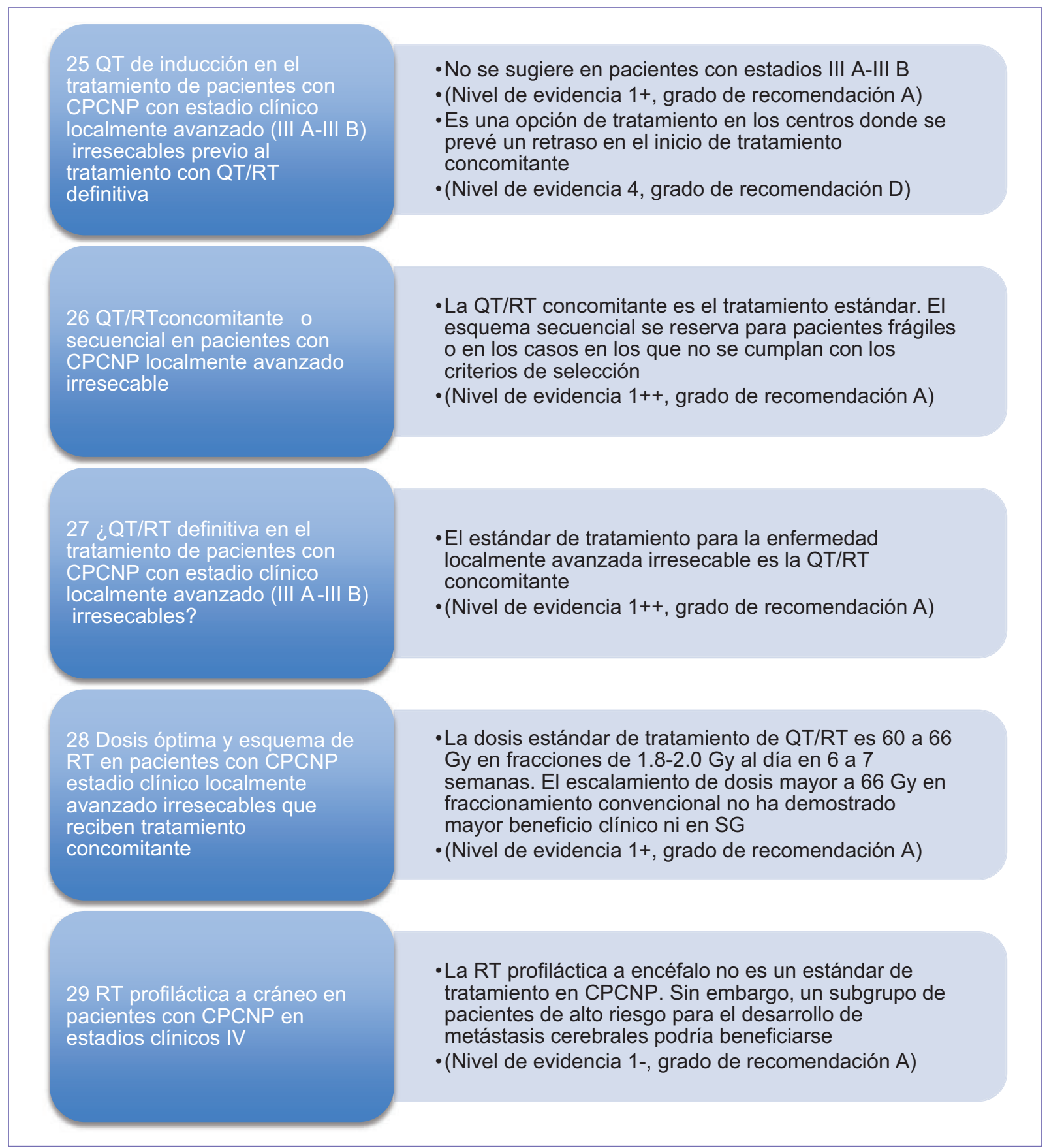

Figura 5. Síntesis de las recomendaciones clínicas para el manejo de cáncer de pulmón de células no pequeñas (CPCNP) en estadio localmente avanzado. (continuación)

incorporadas al cuerpo de evidencia científica, se llevaron a cabo reuniones con el GDG para revisar el texto completo de cada una de las RS para poder extraer los resultados. Se consideraron las medidas de asociación resultado de los metaanálisis reportados en las mismas para determinar el tamaño del efecto global, ya fuere de la razón de momios (odds ratio), el riesgo relativo (relative risk) o la diferencia de los promedios ponderados de los efectos (weighted mean estimate of the effect) de acuerdo a los distintos desenlaces definidos por el GDG. Para estudios de prueba diagnóstica es importante considerar otras medidas de asociación, como la sensibilidad, la especificidad y los valores predictivos positivos y predictivos negativos.

En los casos de las preguntas clínicas en donde no se encontraron RS publicadas de buena calidad, se 


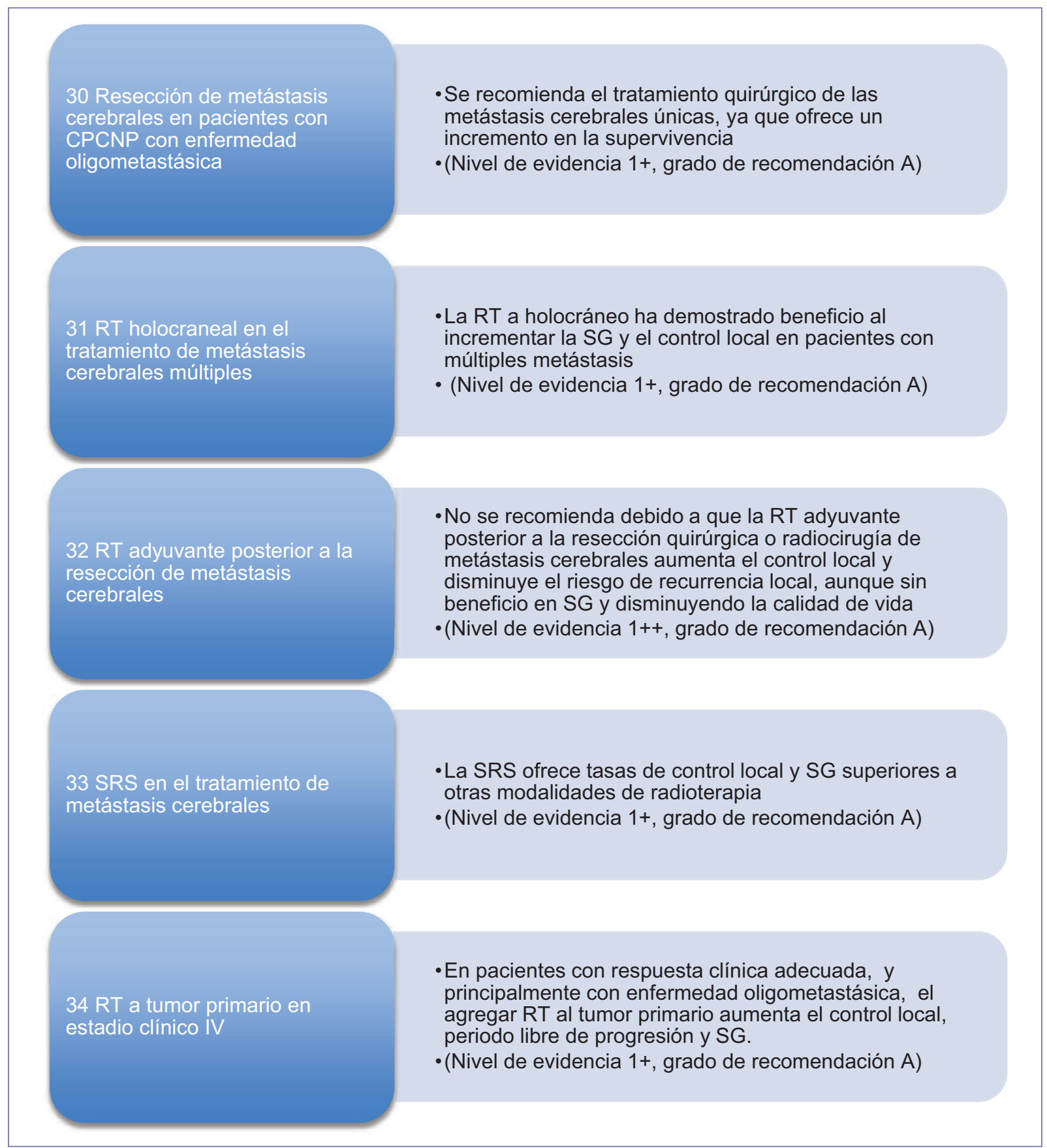

Figura 6. Síntesis de las recomendaciones clínicas para el manejo de cáncer de pulmón de células no pequeñas (CPCNP) en estadio avanzado.

llevó a cabo la RS para identificar estudios clínicos. Una vez hecha la evaluación de calidad y de posibilidad de sesgo, se llevó a cabo el metaanálisis.

Lo primero que se llevó a cabo fue definir la naturaleza de los valores de acuerdo con el tipo de desenlace a estudiar. Una vez extraídas las medidas de asociación, se determinó el grado de heterogeneidad entre los resultados de los estudios, para ello se utilizó la prueba
Q de Der Simonian y Laird. Una vez que se demostró que la heterogeneidad no era significativa, se llevó a cabo el metaanálisis bajo el modelo de efectos fijos cuando se asumió que no existía heterogeneidad entre los estudios incluidos en la revisión y el modelo de efectos aleatorios cuando se asumió que los estudios incluidos en la revisión constituyen una muestra aleatoria de todos los estudios existentes. En los casos pertinentes, 


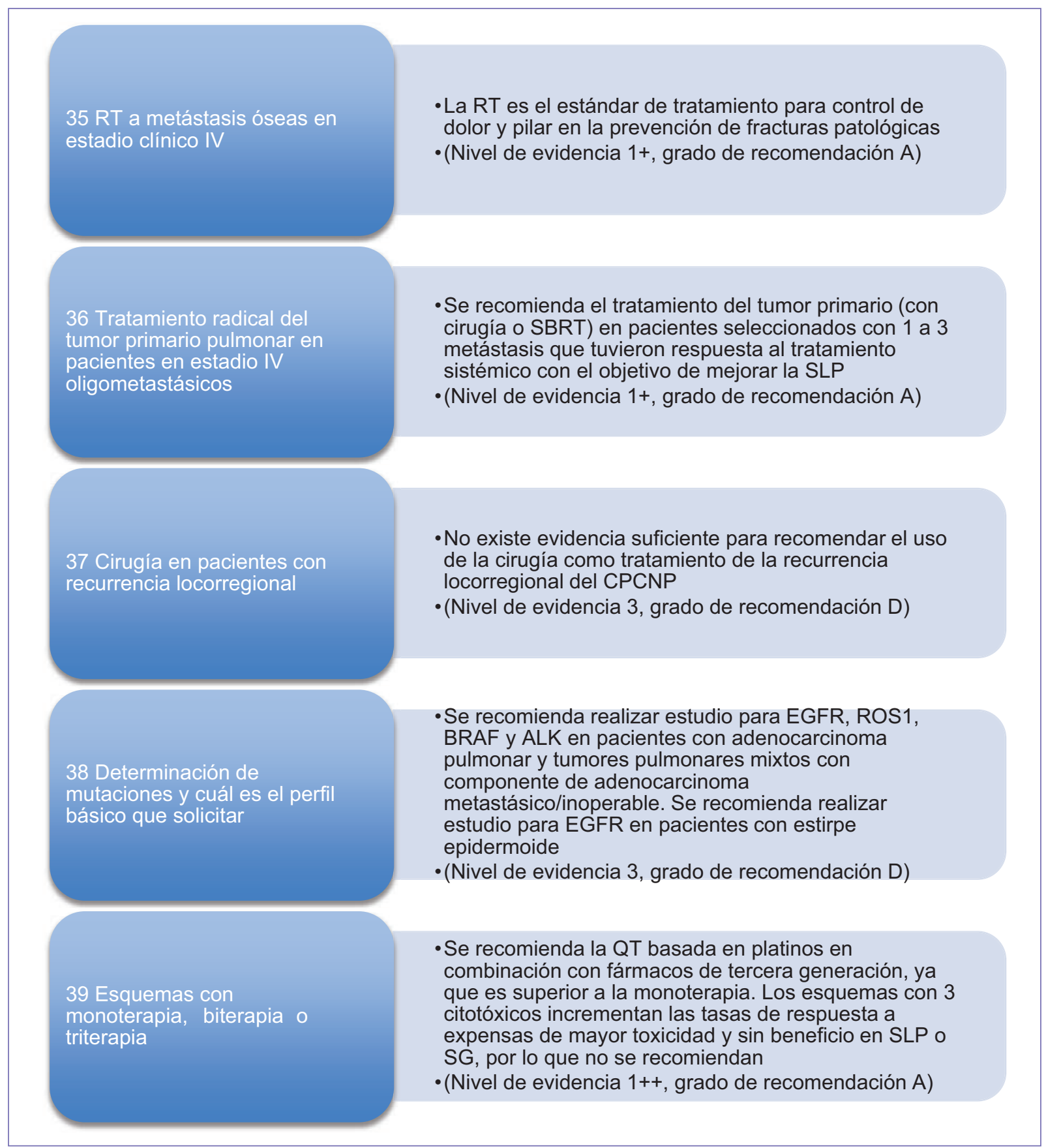

Figura 6. Síntesis de las recomendaciones clínicas para el manejo de cáncer de pulmón de células no pequeñas (CPCNP) en estadio avanzado. (continuación)

se presenta la información en una gráfica de forest plot, en la que se pretendió mostrar el efecto estimado en cada estudio junto con el valor obtenido combinando los resultados de todos los estudios, acompañados por sus respectivos intervalos de confianza. La gráfica contiene además la línea vertical del valor correspondiente a la ausencia de efectos (RR: 1 o diferencia de medias: 0) y los límites de relevancia clínica determinando si las diferencias, además de alcanzar significancia estadística, son de una magnitud relevante.

\section{Consenso formal de expertos}

El método Delphi de consenso formal es el recomendado en el escenario de desarrollo de una GPC. Es un método sistemático, interactivo, iterativo y que se basa en 


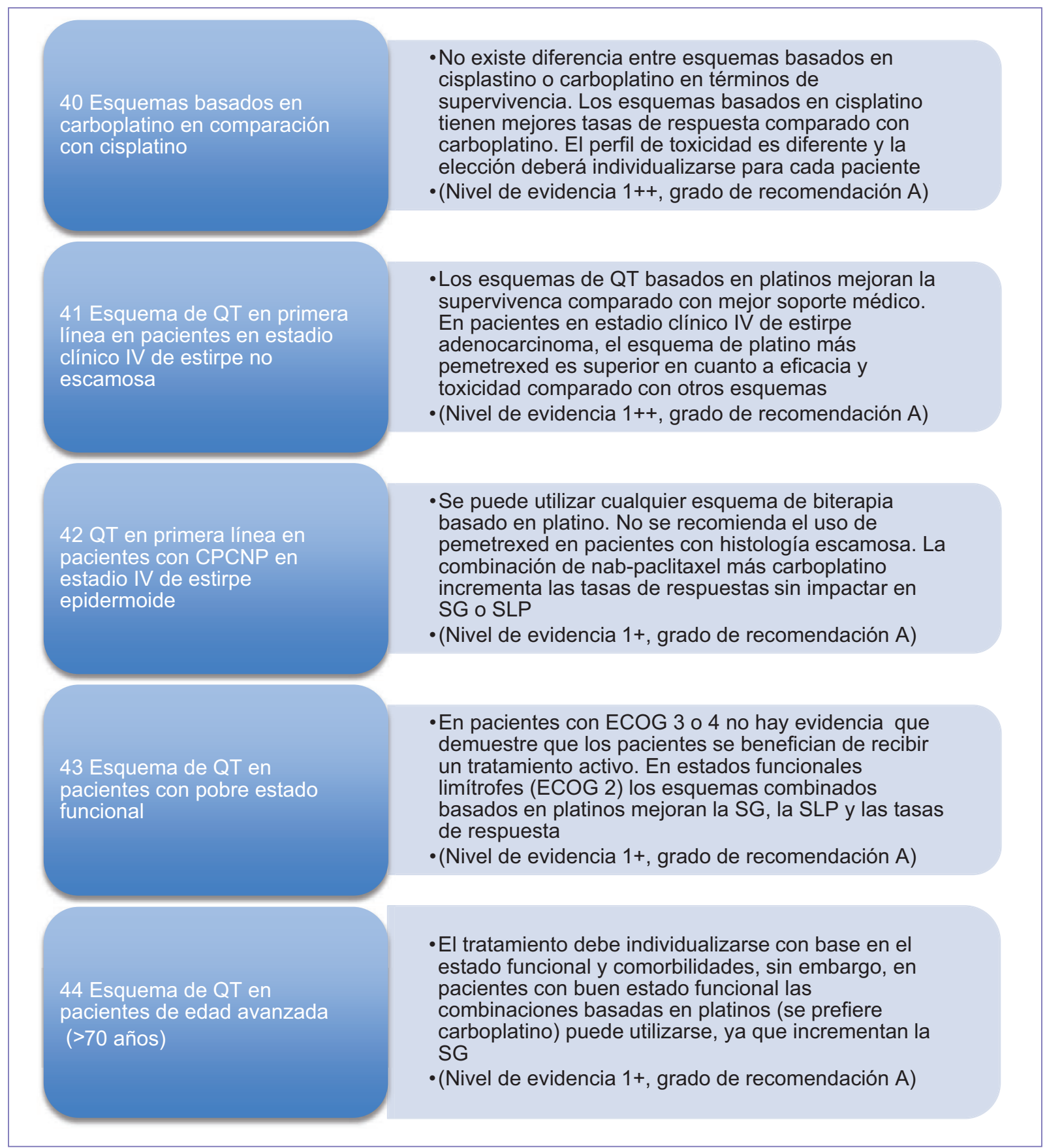

Figura 6. Síntesis de las recomendaciones clínicas para el manejo de cáncer de pulmón de células no pequeñas (CPCNP) en estadio avanzado. (continuación)

la reunión de un grupo de expertos. Cada uno de los expertos contestan preguntas, las cuales pueden ser ajustadas de acuerdo con las respuestas en distintas rondas posteriores. En cada una de esta ronda de preguntas y respuestas, a las cuales se les puede dar un carácter cualitativo y/o cuantitativo, un grupo más reducido perteneciente al GDG, en el cual se encuentran los coordinadores generales y los coordinadores metodológicos de la
GPC, lleva a cabo la integración de las respuestas de todos los expertos de la ronda previa y hacen el ajuste del texto que logre mejorar el porcentaje de acuerdo entre ellos. Es deseable que los expertos revisen su respuesta previa y consideren la nueva respuesta para dirigirse a un porcentaje más alto de acuerdo. Finalmente, el proceso se detiene cuando se alcanza un grado mínimo de consenso entre los expertos. 


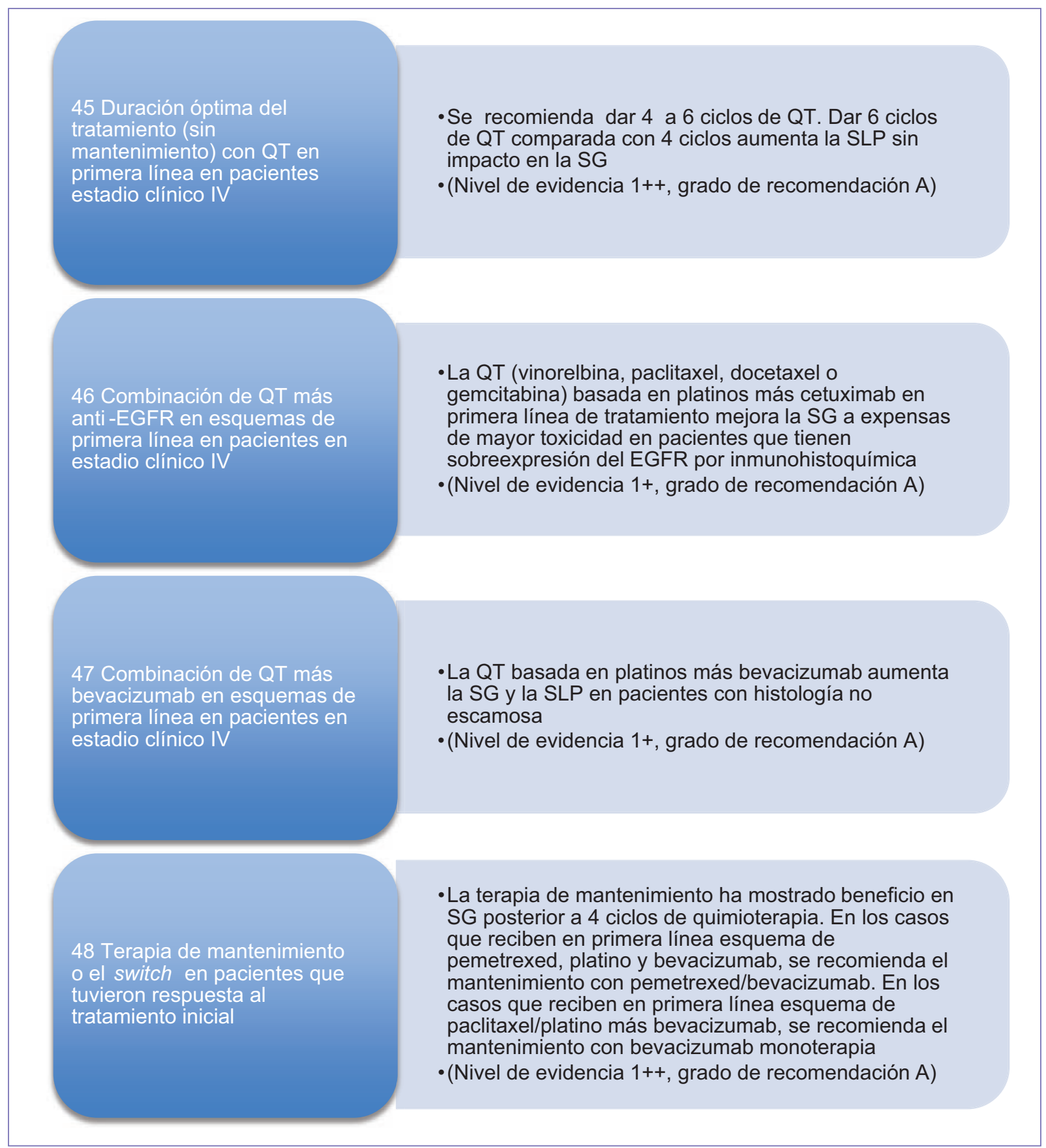

Figura 6. Síntesis de las recomendaciones clínicas para el manejo de cáncer de pulmón de células no pequeñas (CPCNP) en estadio avanzado. (continuación)

Los coordinadores del GDG establecieron un grupo nuclear (core group) que trabajó de cerca cada uno de los documentos y pasos clave en el desarrollo de esta GPC. De igual forma, los coordinadores metodológicos apoyaron durante todo el proceso. Las recomendaciones clínicas fueron redactadas y propuestas por el grupo nuclear con base en la evidencia científica identificada, evaluada, extraída y sintetizada. La estructura que se le dio a la información permitió que las contribuciones de los expertos fueran consensuadas y recogidas de manera que se pudieran desarrollar los textos que se exponían a consideración al resto del GDG. El grupo nuclear llevó el control de la interacción entre los participantes procesando la información y filtrando el contenido relevante. Esto nos permitió reducir de manera importante el efecto negativo de las discusiones cara a 


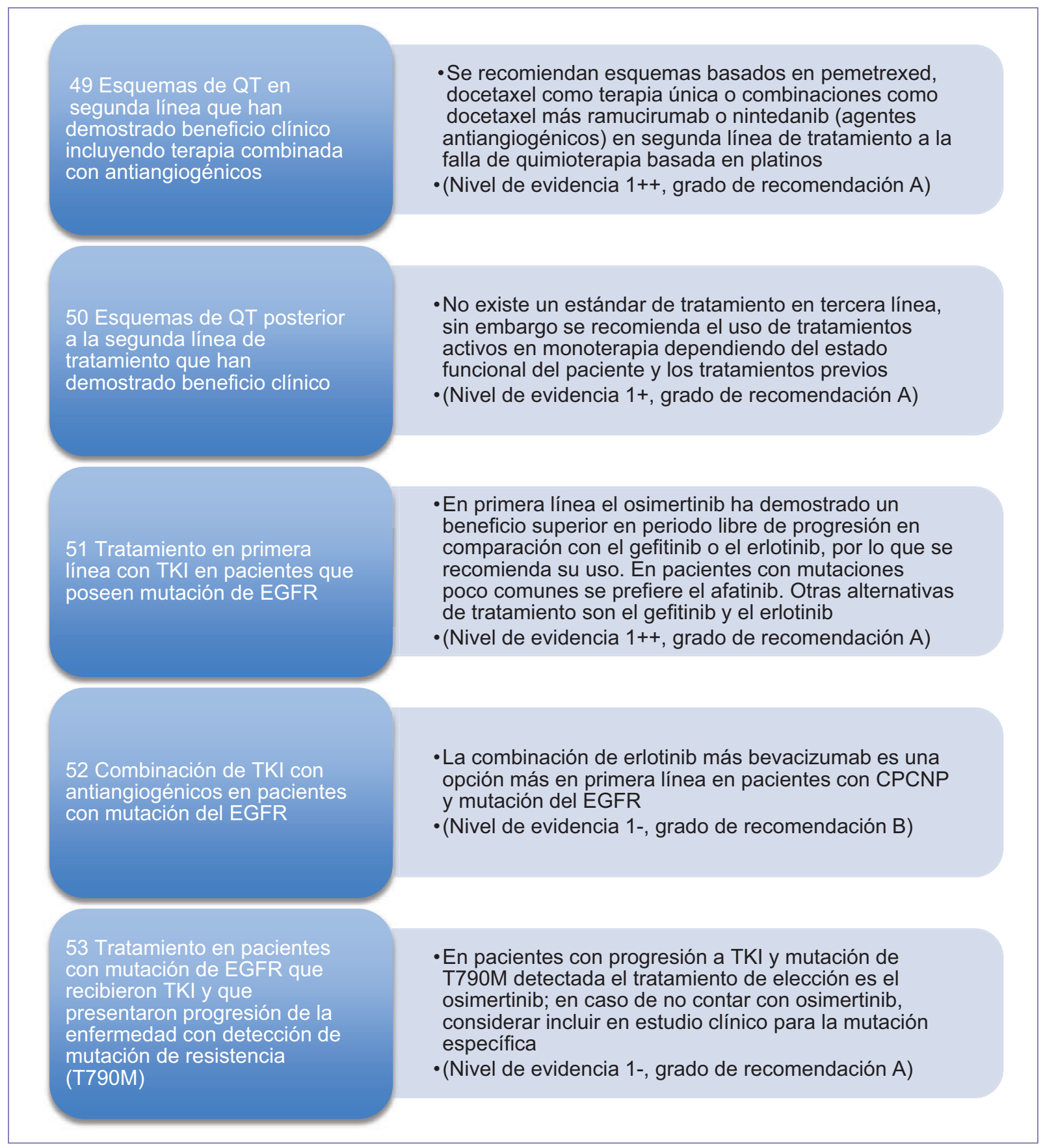

Figura 6. Síntesis de las recomendaciones clínicas para el manejo de cáncer de pulmón de células no pequeñas (CPCNP) en estadio avanzado. (continuación)

cara entre los expertos y resolvió los problemas que se observan en las dinámicas de grupo habitualmente.

Una vez que los miembros del GDG revisaron la redacción de las recomendaciones clínicas y la evidencia científica identificada y evaluada en su calidad, se determinó el grado de acuerdo en el texto utilizando una escala de Likert. La escala de Likert empleada va del 1 al 9 , el número 1 determina que el experto está
«Totalmente en desacuerdo» con el planteamiento de la recomendación y el número 9 determina que el experto está «Totalmente de acuerdo» con esta. Los números intermedios manifiestan que el experto no tiene una postura en el planteamiento o la red acción de la recomendación (Tabla 3).

Internacionalmente, se ha definido el $70 \%$ como un porcentaje mínimo deseable de acuerdo entre los 


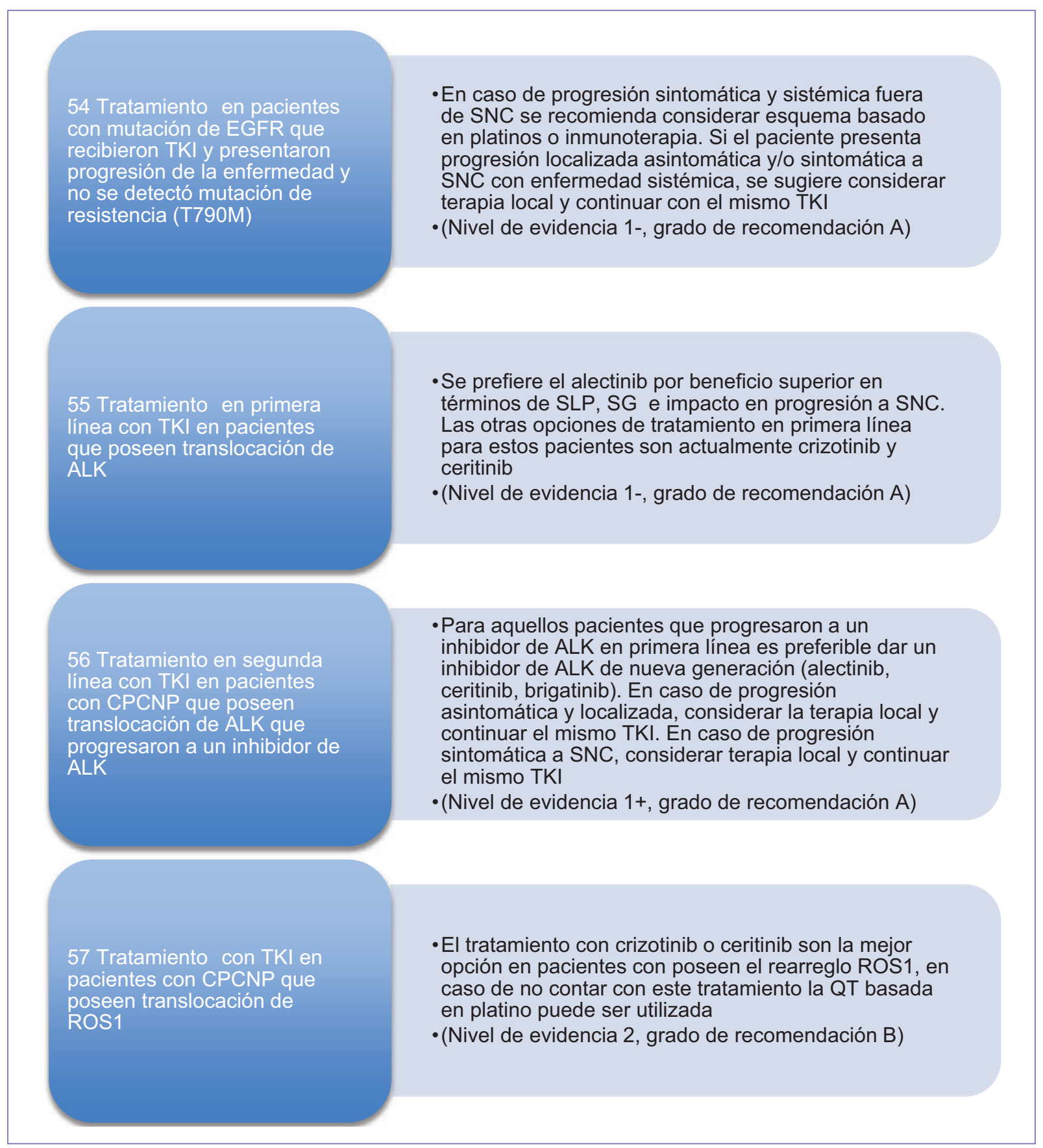

Figura 6. Síntesis de las recomendaciones clínicas para el manejo de cáncer de pulmón de células no pequeñas (CPCNP) en estadio avanzado. (continuación)

expertos participantes en un Panel Delphi. Cuando al menos el $70 \%$ de los expertos han manifestado estar de acuerdo con la recomendación clínica (calificación entre 7 y 9) se considera que se ha llegado a un consenso. Además de evaluar el porcentaje de expertos que califican la recomendación, se llevó a cabo el cálculo de las medidas de tendencia central y de dispersión. Se calculó la media, mediana, moda, desviación estándar y el recorrido de los rangos intercuartiles. Se estableció un mínimo de 7.0 en la media como criterio para alcanzar un grado mínimo de consenso. Se empleó un sistema electrónico anónimo para que los integrantes del GDG calificaran cada recomendación de manera anónima que permitía obtener la estadística de las calificaciones en tiempo real. 


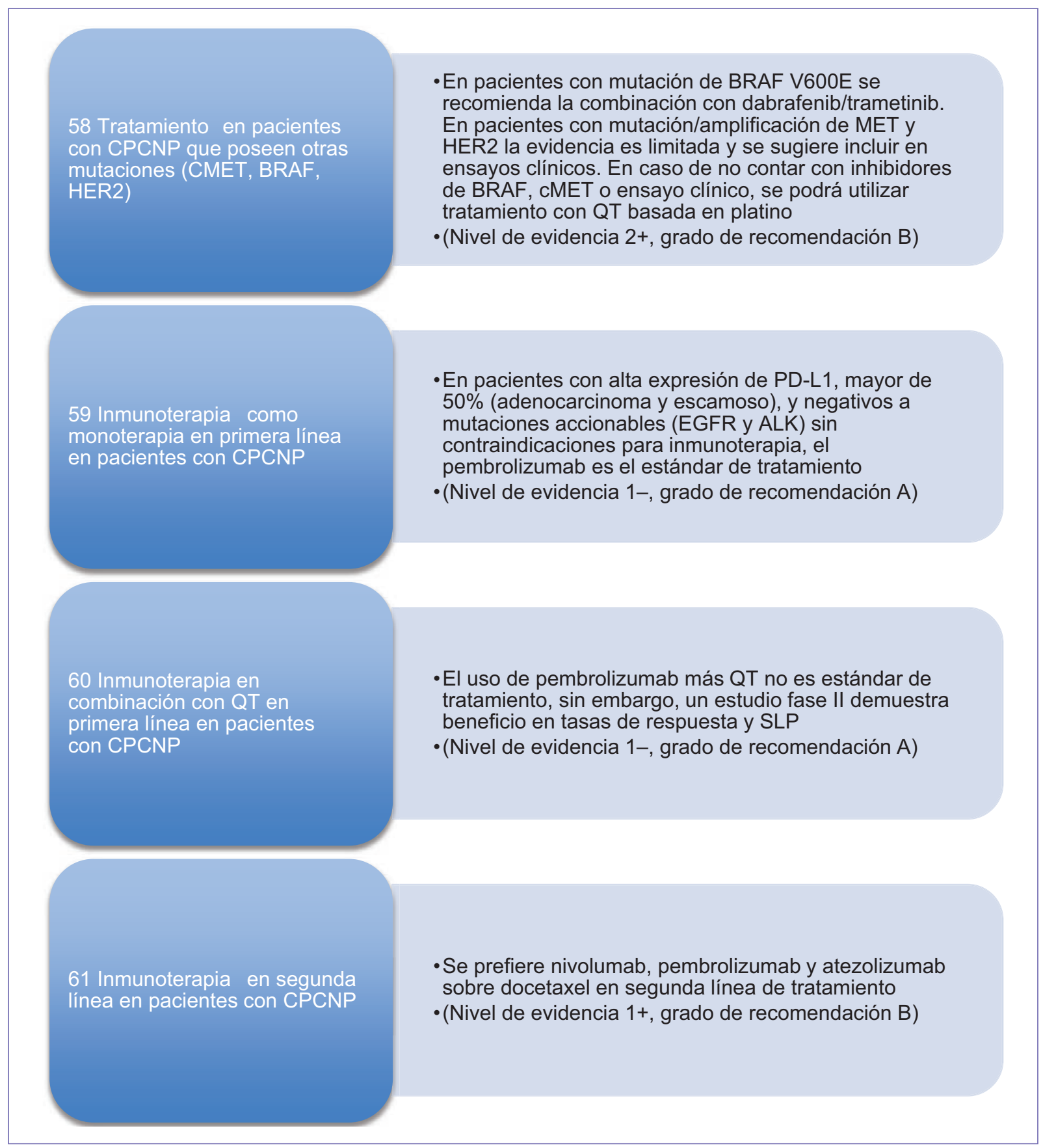

Figura 6. Síntesis de las recomendaciones clínicas para el manejo de cáncer de pulmón de células no pequeñas (CPCNP) en estadio avanzado. (continuación)

\section{Redacción de las recomendaciones}

Los miembros del GDG nuclear se reunieron en diversas ocasiones para revisar el cúmulo de evidencia que responde a las preguntas clínicas estructuradas y de acuerdo con el nivel de evidencia poder determinar el grado de recomendación y la redacción de estas. Las recomendaciones clínicas deben de proveer guía para los tomadores de decisión, es por ello que el GDG tuvo cuidado en que la redacción evitará la ambigüedad al redactarlas. Se tomó en cuenta la evidencia científica, pero el GDG también consideró su experiencia clínica en la redacción de las recomendaciones; estas consideraron también la relación riesgo/beneficio para establecer la toma de decisiones. 


\section{Programa de involucramiento de los pacientes}

La importancia de recabar los valores y preferencias de los pacientes durante el desarrollo de una GPC es cada vez más patente en la literatura internacional. Cada vez más organizaciones internacionales elaboran programas para facilitar el involucramiento de los pacientes en el proceso de desarrollo de estas. La Sociedad Mexicana de Oncología, comprometida por mejorar la calidad de la atención clínica en todos los padecimientos oncológicos, hizo extensiva la invitación a participar en el desarrollo de la GPC a una de las asociaciones de pacientes con mayor trayectoria en el tratamiento de padecimientos oncológicos. Se solicitó que la asociación propusiera un grupo de representantes para validar y proponer modificaciones a las recomendaciones clínicas y el documento final. Los pacientes fueron parte de las mesas de discusión en conjunto con los expertos clínicos durante el desarrollo de la GPC.

\section{Cuerpo de la evidencia}

Se realizaron búsquedas para identificar GPC en las bases de datos descritas anteriormente. Además, se llevaron a cabo 25 estrategias de búsqueda exhaustiva de la literatura en PubMed y Embase (Anexo C) para identificar RS de la literatura con o sin metaanálisis de acuerdo a estrategias validadas internacionalmente. Se elaboró un diagrama de flujo de los estudios que se encontraron y que fueron eliminados en la primera ronda de revisión (Fig. 3).

\section{Recomendaciones clínicas}

Este documento resume las recomendaciones emitidas por el grupo de expertos con base en la mejor evidencia científica (Figs. 4-6).

\section{Bibliografía}

1. Arrieta O, Guzman-de-Alba E, Alba-Lopez LF, Acosta-Espinoza A, Alatorre-Alexander J, Alexander-Meza JF, et al. Consenso nacional de diagnóstico y tratamiento del cáncer de pulmón de células no pequeñas. Rev Invest Clin. 2013;65 Suppl 1:S5-84.

2. Spiro SG, Silvestri GA. One hundred years of lung cancer. Am J Respir Crit Care Med. 2005;172(5):523-9.
3. Tabaquismo, principal causa de cáncer de pulmón [Internet]. México: Secretaría de Salud[fecha de publicación: 5/04/2017]. Disponible en: https://www.gob.mx/salud/prensa/144-tabaquismo-principal-causa-de-cancer-de-pulmon

4. Tang Y, Qiao G, Xu E, Xuan Y, Liao M, Yin G. Biomarkers for early diagnosis, prognosis, prediction, and recurrence monitoring of non-smaII cell lung cancer. Onco Targets Ther. 2017;10:4527-34.

5. Lopez-Campos JL, Ruiz-Ramos M, Fernandez E, Soriano JB. Recent lung cancer mortality trends in Europe: effect of national smoke-free legislation strengthening. Eur J Cancer Prev. 2018;27(4):296-302.

6. Raez LE, Cardona AF, Santos ES, Catoe H, Rolfo C, Lopes G, et al. The burden of lung cancer in Latin-America and challenges in the access to genomic profiling, immunotherapy and targeted treatments. Lung cancer. 2018;119:7-13.

7. Arrieta O, Lopez-Mejia M, Macedo-Perez EO, Corona-Cruz JF. Proposals for the prevention of lung cancer in the health system of Mexico. Salud Publica Mex. 2016;58(2):274-8.

8. Barron F, Zatarain-Barron ZL, Cardona AF, Arrieta O. Extending the curve: survival of EGFR-mutated lung cancer patients in the 21 (st) century. J Thorac Dis. 2018;10(3):1265-8.

9. Hernandez-Garduno E, Ocana-Servin HL. Lung cancer mortality trends in Mexico, 1999-2014. Salud Publica Mex. 2018;60(3):366-9.

10. Zill OA, Banks KC, Fairclough SR, Mortimer S, Vowles JV, Mokhtari R, et al. The landscape of actionable genomic alterations in cell-free circulating tumor DNA from 21,807 advanced cancer patients. Clin Cancer Res. 2018;24(15):3528-38.

11. Raez LE, Santos ES, Rolfo C, Lopes G, Barrios C, Cardona A, et al. Challenges in Facing the Lung Cancer Epidemic and Treating Advanced Disease in Latin America. Clin Lung Cancer. 2017;18(1):e71-9.

12. Orozco-Morales M, Soca-Chafre G, Barrios-Bernal P, Hernandez-Pedro N, Arrieta O. Interplay between Cellular and Molecular Inflammatory Mediators in Lung Cancer. Mediators Inflamm. 2016;2016:3494608.

13. Politi K, Herbst RS. Lung cancer in the era of precision medicine. Clin Cancer Res. 2015;21(10):2213-20.

14. Sackett DL, Rosenberg WM, Gray JA, Haynes RB, Richardson WS. Evidence based medicine: what it is and what it isn't. BMJ. 1996;312(7023):71-2.

15. Myriam Hunink MG, Weinstein MC, Wittenberg E, Drummond MF, Pliskin JS, Wong JB, et al. Decision making in health and medicine. Integrating evidence and values. Cambridge University Press; 2014.

16. Bate L, Hutchinson A, Underhill J, Maskrey N. How clinical decisions are made. Br J Clin Pharmacol. 2012;74(4):614-20.

17. Higgins JPT, Altman DG, Gøtzsche PC, Jüni P, Moher D, Oxman AD, et al. The Cochrane Collaboration's tool for assessing risk of bias in randomised trials. BMJ. 2011;343:d5928.

18. Shekelle PG, Woolf SH, Eccles M, Grimshaw J. Developing guidelines. BMJ. 1999;318(7183):593-6.

19. Grimshaw J, Russell I. Achieving health gain through clinical guidelines. I: Developing scientifically valid guidelines. Qual Health Care. 1993; 2(4):243-8.

20. Hayward RS. Clinical practice guidelines on trial. CMAJ. 1997;156(12): 1725-7.

21. Institute of Medicine (US) Committee on Standards for Developing Trustworthy Clinical Practice Guidelines; Robin G, Michelle M, Dianne MiIler W, Sheldon G, Earl S, editores. Clinical Practice Guidelines We Can Trust. Washington, DC: National Academies Press (US); 2011.

22. Institute of Medicine (U.S.). Committee on Clinical Practice Guidelines. Marilyn JF, Kathleen NL, editoras. Guidelines for Clinical Practice: From Development to Use. Washington, DC: National Academies Press; 1992.

23. The guidelines manual: Process and methods. [Internet] National Institute for Health and Care Excellence: Clinical Guidelines [fecha de publicación: noviembre 2012]. Disponible en: https://www.nice.org.uk/process/ pmg6/resources

24. Health. Nlo. Retirement of the National Institutes of Health Consensus Development Program. [Available from: http://consensus.nih.gov. LA INSTITUCIÓN LO HA RETIRADO

25. Network. GI. Guideline International Network Homepage. Disponible en: https://www.g-i-n.net/

26. Harbour R, Miller J. A new system for grading recommendations in evidence based guidelines. BMJ. 2001;323(7308):334-6.

27. Mayorga-Butrón JL, Velasco-Hidalgo L, Ochoa-Carrillo FJ. Guías de Práctica Clínica Basadas en evidencia, cerrando la brecha entre el conocimiento científico y la toma de decisiones clínicas. Documento de la serie MBE, 3 de 3. Gac Mex Oncol. 2015;14:329-34. 


\section{Anexos}

\section{Anexo A \\ Documento de alcances de la Guia de Práctica Clínica}

\section{Título de la Guía de Práctica Clínica}

Guía de Práctica Clínica (GPC) Nacional para el tratamiento del cáncer de pulmón de células no pequeñas (CPCNP) en estadios tempranos, localmente avanzados y metastásicos.

\section{Título abreviado}

Guía de Práctica Clínica Nacional en CPCNP.

\section{Antecedentes}

- La Sociedad Mexicana de Oncología en colaboración con el Consejo Mexicano de Oncología y el Centro Nacional de Excelencia Tecnológica apoyados metodológicamente por la agencia Ibero American Agency for Development and Assessment of Health Technologies llevarán a cabo el desarrollo de una GPC que cumple con los más altos estándares internacionales sobre el tratamiento del CPCNP, para apoyar a los especialistas en su toma de decisiones clínicas y brindar recomendaciones puntuales sobre los distintos tópicos a este respecto.

- Esta GPC cumple con estándares bien validados publicados por distintas instituciones internacionales como el Instituto de Medicina de EE.UU. (IOM, por sus siglas en inglés), el Instituto de Excelencia Clínica (NICE, por sus siglas en inglés), la Red Colegiada para el Desarrollo de Guías de Escocia (SIGN, por sus siglas en inglés) y la Red Internacional de Guías (GIN, por sus siglas en inglés).

- Se llevará también una estrategia de promoción, diseminación e implementación de las recomendaciones contenidas en esta GPC para apoyar a los distintos tomadores de decisión, tanto elaboradores de políticas en salud, administrativos, médicos especialistas, como a otros profesionales de la salud, pacientes y sus cuidadores para lograr elevar la calidad en la atención clínica en estos pacientes.

\section{Justificación para el desarrollo de la Guía de Práctica Clínica}

El cáncer de pulmón (CP) es la principal causa de muerte por cáncer en el mundo. De acuerdo con los datos estimados por el GLOBOCAN, la incidencia y mortalidad mundiales por CP estimadas para el año 2012 fueron de 23.1 y 19.7 casos por 100,000 habitantes.

Se calcula que la incidencia de casos nuevos se incremente de 14 millones de casos nuevos en 2012 a 22 millones en el año 2030. La adicción al tabaquismo es el principal factor de riesgo para el desarrollo de algunos tumores, causando el $22 \%$ de las muertes por cáncer y alrededor del $71 \%$ de las muertes por CP. Además de $\mathrm{CP}$, el tabaquismo contribuye a la mortalidad en seis de las ocho principales causas de muerte en el mundo. EI CP es una enfermedad que puede ser prevenida evitando factores de riesgo modificables. Para México, la incidencia y mortalidad por CP estimadas para el 2012 fueron de 7.5 y 6.7 casos por 100,000 habitantes, siendo la primera causa de mortalidad.

Sin lugar a dudas, el CP representa un problema de salud pública en México y en el mundo, por ello es importante incorporar la evidencia científica de más alta calidad que se produce en todo el mundo para la toma de decisiones clínicas. Esto con la finalidad de asistir a los distintos tomadores de decisión y de esta forma mejorar la calidad de la atención, por lo que está justificada la elaboración de la GPC.

\section{Población}

\section{Población incluida}

- Pacientes de 18 años o más con diagnóstico histopatológico de CPCNP.

\section{Población excluida}

- Cualquier cáncer de pulmón en menores de 18 años.

- Mujeres embarazadas o lactantes.

- Cáncer de pulmón de células pequeñas.

- Diagnóstico de otros tumores de origen pulmonar poco frecuentes.

- Diagnóstico de tumores de comportamiento benigno.

\section{Tópicos clínicos que no serán considerados}

- Diagnóstico.

- Tratamiento psicológico.

- Tratamiento de cuidados paliativos.

- Información para pacientes y cuidadores. 
- Tratamiento de complicaciones secundarias a tratamientos.

- Tratamiento en pacientes embarazadas.

- Consejo genético en cáncer de pulmón.

\section{Escenarios clínicos en donde se} aplicarán las recomendaciones de la Guía de Práctica Clínica

- Segundo y tercer nivel de atención.

- Oncólogos quirúrgicos de instituciones públicas y privadas.

- Médicos nucleares en instituciones públicas y privadas.

- Radiooncólogos en instituciones públicas y privadas.

- Oncólogos médicos en instituciones públicas y privadas.

- Cirujanos de tórax.

\section{Procesos clínicos que serán considerados en la Guía de Práctica Clínica}

\section{Estadios clínicos}

- Para determinar la extensión de la enfermedad se emplea el sistema TNM (tumor, nodes [ganglios] y metástasis) en su 7. ${ }^{a}$ edición, de acuerdo con las directrices publicadas por la American Joint Committee on Cancer y la International Association for the Study of Lung Cancer.

\section{Manejo terapéutico}

- Tratamiento quirúrgico.

- Radioterapia (RT).

- Quimioterapia (QT).

- Terapia blanco.

- Inmunoterapia.

\section{Intervenciones y tratamientos que serán} considerados

- Tratamiento quirúrgico:

- Tratamiento quirúrgico en estadios tempranos.

- Resección sublobar.

- Lobectomía.

- Lobectomía por cirugía mínimamente invasiva vs. cirugía abierta.

- Neumonectomía.

- Manejo del mediastino en estadios tempranos.

- Muestreo mediastinal.

- Disección mediastinal.

- Tratamiento del N2 incidental.
- Tratamiento quirúrgico posterior al tratamiento con QT o QT/RT concomitante en estadios localmente avanzados.

- Neumonectomía vs. lobectomía.

- Tratamiento quirúrgico radical en estadio clínico IV con enfermedad oligometastásica posterior a respuesta al tratamiento sistémico.

- Tratamiento quirúrgico de la recaída.

- Radioterapia:

- RT estereotáxica corporal en estadio clínico temprana.

- Radiología intervencionista.

- Ablación por radiofrecuencia en estadios clínicos tempranas.

- RT preoperatoria.

- RT adyuvante.

- Secuencial vs. concomitante con QT.

- N2 incidental.

- Márgenes positivos.

- Dosis y esquemas de RT.

- RT a tumor primario en estadio clínico IV con enfermedad oligometastásica posterior a respuesta al tratamiento sistémico.

- Tratamiento de las metástasis cerebrales.

- Tratamiento de la enfermedad sintomática.

- RT holocraneal total.

- RT estereotáxica craneal.

- Tratamiento de la enfermedad metastásica a hueso.

- Profilaxis cerebral en pacientes con CPCNP.

- Quimioterapia:

- QT neoadyuvante en estadio temprano.

- QT adyuvante.

- Enfermedad temprana completamente resecada de alto riesgo.

- Estadio clínico II y III A resecable.

$$
\text { - QT } \pm \text { RT. }
$$

- QT en estadio clínico III A potencialmente resecable.

- QT neoadyuvante

- QT/RT concomitante preoperatoria.

- QT en estadio clínico III A voluminosa irresecable y III B

- QT de inducción seguida de RT.

- QT/RT concomitante definitiva.

- QT de consolidación.

- QT/RT en tumores del sulcus superior.

- Genotipificación en cáncer de pulmón.

- Primera línea en enfermedad metastásica.

- Monoterapia vs. combinada.

- Cisplatino vs. carboplatino. 
- Esquemas de QT en histología adenocarcinoma.

- Esquemas de QT en histología epidermoide.

- Pacientes con pobre estado funcional.

- Pacientes de edad avanzada.

- Duración optima del tratamiento con QT en primera línea.

- QT en combinación con bevacizumab.

- QT en combinación con anti-EGFR.

- Cetuximab.

- Necitumumab.

- Terapia de mantenimiento.

- Segunda línea temprana o switch.

- Segunda línea en enfermedad metastásica.

- Esquemas y combinaciones con antiangiogénicos.

- Bevacizumab.

- Ramucirumab.

- Nintedanib.

- QT posterior a segunda línea en enfermedad metastásica.

- Terapias blanco:

- Uso de terapia blanco en estadios tempranos.

- Uso de inhibidores de tirosina cinasa (TKI) adyuvante.

- Inhibidores de angiogénesis en estadio temprano.

- Primera línea en pacientes con mutaciones de EGFR sensibles a TKI.

- Monoterapia.

- TKI más inhibidor de angiogénesis.

- Segunda línea en pacientes con mutaciones de EGFR.

- Mutación de resistencia (T790M).

- Sin mutación de resistencia (T790M).

- Primera línea en pacientes con traslocación de ALK.

- Segunda línea en pacientes con traslocación de ALK.
- Primera línea en pacientes con traslocación de ROS1.

- Tratamiento de otras mutaciones con terapia blanco.

- CMET

- HER2

- BRAF

- Inmunoterapia:

- Inmunoterapia en primera línea para la enfermedad metastásica.

- Monoterapia.

- QT combinada con inmunoterapia.

- Inmunoterapia en segunda línea para la enfermedad metastásica.

\section{Desenlaces clínicos que ser evaluados}

\section{Desenlace}

\section{Relevancia}

Supervivencia global 9

Supervivencia libre de enfermedad 9

Supervivencia libre de progresión 9

Calidad de vida

Tasa de respuesta global

Incidencia de eventos adversos

Mortalidad relacionada al tratamiento

Tiempo a la progresión

Recurrencia locoregional

Recurrencia a distancia

8

8

8

8

8

7

7

\section{Aportaciones clínicas que consideramos de relevancia en la Guía de Práctica Clínica}

El objetivo de esta GPC es demostrar cómo debe ser el diagnóstico y tratamiento del CPCNP en México basado en evidencia clínica nacional e internacional. 


\section{Anexo B}

Base de datos de preguntas clínicas

\begin{tabular}{|c|c|c|c|c|c|}
\hline \multicolumn{6}{|c|}{$\begin{array}{l}\text { Guía de Práctica Clínica Nacional para el tratamiento del cáncer de pulmón en estadios tempranos, localmente avanzados y } \\
\text { metastásicos }\end{array}$} \\
\hline & Estadio & Área evaluada & Población & Intervención & Pregunta clínica estructurada \\
\hline 1 & $\begin{array}{l}\text { Estadio clínico } \\
\text { temprano }\end{array}$ & Cirugía & $\begin{array}{l}\text { Pacientes mayores de } \\
18 \text { años médicamente } \\
\text { operables }\end{array}$ & $\begin{array}{l}\text { Tipos de resecciones } \\
\text { quirúrgicas }\end{array}$ & $\begin{array}{l}\text { ¿Cuál es la resección } \\
\text { quirúrgica estándar en } \\
\text { pacientes con CP en estadios } \\
\text { clínicos tempranas? }\end{array}$ \\
\hline 2 & $\begin{array}{l}\text { Estadio clínico } \\
\text { temprano }\end{array}$ & Cirugía & $\begin{array}{l}\text { Pacientes mayores de } \\
18 \text { años médicamente } \\
\text { operables }\end{array}$ & Disección mediastinal & $\begin{array}{l}\text { ¿Cuál es el mejor método para } \\
\text { la estadificación ganglionar } \\
\text { del mediastino durante la } \\
\text { cirugía resectiva en pacientes } \\
\text { con CP en estadios clínicos } \\
\text { tempranas? }\end{array}$ \\
\hline 3 & $\begin{array}{l}\text { Estadio clínico } \\
\text { temprano }\end{array}$ & Cirugía & $\begin{array}{l}\text { Pacientes mayores de } \\
18 \text { años médicamente } \\
\text { operables }\end{array}$ & Resección por VATS & $\begin{array}{l}\text { ¿La lobectomía por cirugía de } \\
\text { mínima invasión es tan } \\
\text { efectiva como la lobectomía } \\
\text { por toracotomía para el } \\
\text { tratamiento del CPCNP en } \\
\text { estadios tempranos? }\end{array}$ \\
\hline 4 & $\begin{array}{l}\text { Estadio clínico } \\
\text { temprano }\end{array}$ & Cirugía & $\begin{array}{l}\text { Pacientes mayores de } \\
18 \text { años médicamente } \\
\text { operables }\end{array}$ & Ganglio centinela & $\begin{array}{l}\text { ¿Está indicado el } \\
\text { procedimiento de ganglio } \\
\text { centinela en el tratamiento del } \\
\text { CPCNP en estadios } \\
\text { tempranos? }\end{array}$ \\
\hline 5 & $\begin{array}{l}\text { Estadio clínico } \\
\text { temprano }\end{array}$ & $\mathrm{RT}$ & $\begin{array}{l}\text { Pacientes mayores de } \\
18 \text { años médicamente } \\
\text { inoperables }\end{array}$ & RT convencional & $\begin{array}{l}\text { ¿Cuál es el beneficio de la RT } \\
\text { en pacientes con CPCNP en } \\
\text { estadio I inoperables o que } \\
\text { rechacen el tratamiento } \\
\text { quirúrgico? }\end{array}$ \\
\hline 6 & $\begin{array}{l}\text { Estadio clínico } \\
\text { temprano }\end{array}$ & $\mathrm{RT}$ & $\begin{array}{l}\text { Pacientes mayores de } \\
18 \text { años médicamente } \\
\text { inoperables }\end{array}$ & $\mathrm{QT} / \mathrm{RT}$ concomitante & $\begin{array}{l}\text { ¿Ofrece algún beneficio el } \\
\text { tratamiento con } \mathrm{QT} / \mathrm{RT} \\
\text { concomitante en estadio } \\
\text { clínico I inoperables o que } \\
\text { rechacen el tratamiento } \\
\text { quirúrgico? }\end{array}$ \\
\hline 7 & $\begin{array}{l}\text { Estadio clínico } \\
\text { temprano }\end{array}$ & $\mathrm{RT}$ & $\begin{array}{l}\text { Pacientes mayores de } \\
18 \text { años médicamente } \\
\text { inoperables }\end{array}$ & SBRT & $\begin{array}{l}\text { ¿El tratamiento con SBRT es } \\
\text { seguro y eficaz comparado } \\
\text { con la cirugía en pacientes } \\
\text { con CPCNP en estadio I? }\end{array}$ \\
\hline 8 & $\begin{array}{l}\text { Estadio clínico } \\
\text { temprano }\end{array}$ & RT & $\begin{array}{l}\text { Pacientes mayores de } \\
18 \text { años médicamente } \\
\text { inoperables }\end{array}$ & SBRT & $\begin{array}{l}\text { ¿Cuál es la dosis y esquema } \\
\text { óptimo de RT en CPCNP en } \\
\text { estadio I inoperables o que } \\
\text { rechacen el tratamiento } \\
\text { quirúrgico? }\end{array}$ \\
\hline 9 & $\begin{array}{l}\text { Estadio clínico } \\
\text { temprano }\end{array}$ & $\mathrm{RT}$ & $\begin{array}{l}\text { Pacientes mayores de } \\
18 \text { años médicamente } \\
\text { inoperables }\end{array}$ & RT & $\begin{array}{l}\text { ¿Está indicado el tratamiento } \\
\text { con RT a mediastino en } \\
\text { CPCNP en estadio I inoperable } \\
\text { o que rechacen el tratamiento } \\
\text { quirúrgico? }\end{array}$ \\
\hline 10 & $\begin{array}{l}\text { Estadio clínico } \\
\text { temprano }\end{array}$ & $\begin{array}{l}\text { Radiología } \\
\text { intervencionista }\end{array}$ & $\begin{array}{l}\text { Pacientes mayores de } \\
18 \text { años médicamente } \\
\text { inoperables }\end{array}$ & RFA & $\begin{array}{l}\text { ¿El tratamiento con RFA es } \\
\text { seguro y eficaz comparado } \\
\text { con la RT en pacientes con } \\
\text { CPCNP en estadio I } \\
\text { inoperables? }\end{array}$ \\
\hline
\end{tabular}


Anexo B. Base de datos de preguntas clínicas (continuación)

Base de datos de preguntas clínicas

Guía de Práctica Clínica Nacional para el tratamiento del cáncer de pulmón en estadios tempranos, localmente avanzados y metastásicos

\begin{tabular}{|c|c|c|c|c|c|}
\hline & Estadio & Área evaluada & Población & Intervención & Pregunta clínica estructurada \\
\hline 11 & $\begin{array}{l}\text { Estadio clínico } \\
\text { temprano }\end{array}$ & QT & $\begin{array}{l}\text { Pacientes mayores de } \\
18 \text { años resecados } \\
\text { completamente }\end{array}$ & OT adyuvante & $\begin{array}{l}\text { ¿Cuál es el beneficio de la QT } \\
\text { adyuvante en pacientes } \\
\text { completamente resecados en } \\
\text { estadio clínico I A? }\end{array}$ \\
\hline 12 & $\begin{array}{l}\text { Estadio clínico } \\
\text { temprano }\end{array}$ & QT & $\begin{array}{l}\text { Pacientes mayores de } \\
18 \text { años resecados } \\
\text { completamente }\end{array}$ & QT adyuvante & $\begin{array}{l}\text { ¿Cuál es el beneficio de la QT } \\
\text { adyuvante en pacientes } \\
\text { completamente resecados en } \\
\text { estadio clínico I B con } \\
\text { factores de riesgo para } \\
\text { recurrencia? }\end{array}$ \\
\hline 13 & $\begin{array}{l}\text { Estadio clínico } \\
\text { temprano }\end{array}$ & $\mathrm{OT}$ & $\begin{array}{l}\text { Pacientes mayores de } \\
18 \text { años resecados } \\
\text { completamente }\end{array}$ & OT adyuvante & $\begin{array}{l}\text { ¿Cuáles son los esquemas de } \\
\text { tratamiento recomendados } \\
\text { para el tratamiento adyuvante } \\
\text { en CPCNP? }\end{array}$ \\
\hline 14 & $\begin{array}{l}\text { Estadio clínico } \\
\text { temprano }\end{array}$ & RT & $\begin{array}{l}\text { Pacientes mayores de } \\
18 \text { años resecados } \\
\text { completamente }\end{array}$ & RT adyuvante & $\begin{array}{l}\text { ¿Cuál es el beneficio de la RT } \\
\text { adyuvante en pacientes } \\
\text { completamente resecados en } \\
\text { estadios clínicos tempranas? }\end{array}$ \\
\hline 15 & $\begin{array}{l}\text { Estadio clínico } \\
\text { temprano }\end{array}$ & RT & $\begin{array}{l}\text { Pacientes mayores de } \\
18 \text { años resecados } \\
\text { completamente }\end{array}$ & RT adyuvante & $\begin{array}{l}\text { ¿Cuál es el beneficio de la RT } \\
\text { postoperatoria en pacientes } \\
\text { con estadios clínicos } \\
\text { tempranos y resección } \\
\text { completa, pero con márgenes } \\
\text { positivos y/o N2 incidental no } \\
\text { candidatos a rerresección } \\
\text { quirúrgica? }\end{array}$ \\
\hline 16 & $\begin{array}{l}\text { Estadio clínico } \\
\text { temprano }\end{array}$ & Terapia blanco & $\begin{array}{l}\text { Pacientes mayores de } \\
18 \text { años resecados } \\
\text { completamente }\end{array}$ & $\begin{array}{l}\text { Terapia blanco } \\
\text { adyuvante }\end{array}$ & $\begin{array}{l}\text { ¿Está indicado el uso de } \\
\text { terapia blanco en el } \\
\text { tratamiento adyuvante en } \\
\text { pacientes en quienes se } \\
\text { detecta alguna mutación } \\
\text { sensible a TKI en pacientes } \\
\text { con CPCNP completamente } \\
\text { resecados? }\end{array}$ \\
\hline 17 & $\begin{array}{l}\text { Estadio clínico } \\
\text { temprano }\end{array}$ & QT & $\begin{array}{l}\text { Pacientes mayores de } \\
18 \text { años resecables }\end{array}$ & QT neoadyuvante & $\begin{array}{l}\text { ¿Cuál es el beneficio del } \\
\text { tratamiento con } \mathrm{QT} \\
\text { neoadyuvante en pacientes } \\
\text { con CPCNP en estadios } \\
\text { clínicos tempranos } 0 \\
\text { localmente avanzados } \\
\text { potencialmente resecables? }\end{array}$ \\
\hline 18 & $\begin{array}{l}\text { Estadio clínico } \\
\text { localmente } \\
\text { avanzado (III A) }\end{array}$ & QT & $\begin{array}{l}\text { Pacientes mayores de } \\
18 \text { años potencialmente } \\
\text { resecables }\end{array}$ & QT neoadyuvante & $\begin{array}{l}\text { ¿Cuáles son los esquemas de } \\
\text { tratamiento recomendados } \\
\text { para el tratamiento } \\
\text { neoadyuvante en CPCNP? }\end{array}$ \\
\hline 19 & $\begin{array}{l}\text { Estadio clínico } \\
\text { localmente } \\
\text { avanzado (III A) }\end{array}$ & $\mathrm{QT} / \mathrm{RT}$ & $\begin{array}{l}\text { Pacientes mayores de } \\
18 \text { años EC III A con } \\
\text { enfermedad voluminosa } \\
\text { potencialmente } \\
\text { resecables }\end{array}$ & $\mathrm{QT} / \mathrm{RT}$ & $\begin{array}{l}\text { ¿Cuál es el beneficio de la } \mathrm{QT} / \\
\mathrm{RT} \text { preoperatoria en el } \\
\text { tratamiento de pacientes con } \\
\text { CPCNP con estadio clínico } \\
\text { locamente avanzado (III A) } \\
\text { potencialmente resecables? }\end{array}$ \\
\hline
\end{tabular}


Anexo B. Base de datos de preguntas clínicas (continuación)

Base de datos de preguntas clínicas

Guía de Práctica Clínica Nacional para el tratamiento del cáncer de pulmón en estadios tempranos, localmente avanzados y metastásicos

\begin{tabular}{|c|c|c|c|c|c|}
\hline & Estadio & Área evaluada & Población & Intervención & Pregunta clínica estructurada \\
\hline 20 & $\begin{array}{l}\text { Estadio clínico } \\
\text { localmente } \\
\text { avanzado (III A) }\end{array}$ & RT & $\begin{array}{l}\text { Pacientes mayores de } \\
18 \text { años EC III A con } \\
\text { enfermedad voluminosa } \\
\text { potencialmente } \\
\text { resecables }\end{array}$ & Esquemas de RT & $\begin{array}{l}\text { ¿Cuál es la dosis óptima y } \\
\text { esquema de RT concomitante } \\
\text { en pacientes con CPCNP } \\
\text { locamente avanzado } \\
\text { potencialmente resecable? }\end{array}$ \\
\hline 21 & $\begin{array}{l}\text { Estadio clínico } \\
\text { localmente } \\
\text { avanzado }\end{array}$ & $\mathrm{QT} / \mathrm{RT}$ & $\begin{array}{l}\text { Pacientes mayores de } \\
18 \text { años con tumores del } \\
\text { sulcus superior }\end{array}$ & $\mathrm{QT} / \mathrm{RT}$ & $\begin{array}{l}\text { ¿Cuál es la mejor opción de } \\
\text { tratamiento para los tumores } \\
\text { del sulcus superior? }\end{array}$ \\
\hline 22 & $\begin{array}{l}\text { Estadio clínico } \\
\text { localmente } \\
\text { avanzado (III A) }\end{array}$ & Cirugía & $\begin{array}{l}\text { Pacientes mayores de } \\
18 \text { años EC III A con } \\
\text { enfermedad voluminosa } \\
\text { potencialmente } \\
\text { resecables }\end{array}$ & Cirugía & $\begin{array}{l}\text { ¿Qué pacientes se benefician del } \\
\text { tratamiento quirúrgico posterior } \\
\text { al tratamiento de inducción en } \\
\text { pacientes con CPCNP y estadio } \\
\text { clínico III A por N2? }\end{array}$ \\
\hline 23 & $\begin{array}{l}\text { Estadio clínico } \\
\text { localmente } \\
\text { avanzado (III A) }\end{array}$ & Cirugía & $\begin{array}{l}\text { Pacientes mayores de } \\
18 \text { años EC III A con } \\
\text { enfermedad voluminosa } \\
\text { potencialmente } \\
\text { resecables }\end{array}$ & $\begin{array}{l}\text { Tipos de resecciones } \\
\text { quirúrgicas }\end{array}$ & $\begin{array}{l}\text { ¿En pacientes candidatos a } \\
\text { cirugía posterior al tratamiento } \\
\text { de inducción, qué tipo de } \\
\text { resección ofrece mejores } \\
\text { resultados? }\end{array}$ \\
\hline 24 & $\begin{array}{l}\text { Estadio clínico } \\
\text { localmente } \\
\text { avanzado (III A) }\end{array}$ & QT & $\begin{array}{l}\text { Pacientes mayores de } \\
18 \text { años potencialmente } \\
\text { resecables }\end{array}$ & QT de consolidación & $\begin{array}{l}\text { ¿Qué beneficio ofrece el } \\
\text { tratamiento de consolidación } \\
\text { en pacientes posterior a } \\
\text { tratamiento radical en } \\
\text { pacientes con enfermedad } \\
\text { localmente avanzada? }\end{array}$ \\
\hline 25 & $\begin{array}{l}\text { Estadio clínico } \\
\text { localmente } \\
\text { avanzado } \\
\text { (III A-III B) }\end{array}$ & QT & $\begin{array}{l}\text { Pacientes mayores de } \\
18 \text { años irresecables }\end{array}$ & QT de inducción & $\begin{array}{l}\text { ¿Cuál es el beneficio de la } \mathrm{OT} \\
\text { de inducción en el tratamiento } \\
\text { de pacientes con CPCNP con } \\
\text { estadio clínico locamente } \\
\text { avanzado (III A-III B) } \\
\text { irresecables previo al } \\
\text { tratamiento con QT/RT } \\
\text { definitiva? }\end{array}$ \\
\hline 26 & $\begin{array}{l}\text { Estadio clínico } \\
\text { localmente } \\
\text { avanzado } \\
\text { (III A-III B) }\end{array}$ & QT/RT & $\begin{array}{l}\text { Pacientes mayores de } \\
18 \text { años irresecables }\end{array}$ & $\begin{array}{l}\mathrm{OT} / \mathrm{RT} \text { concomitante } \\
\text { vs. secuencial }\end{array}$ & $\begin{array}{l}\text { En pacientes con CPCNP } \\
\text { localmente avanzado } \\
\text { irresecable, ¿qué modalidad } \\
\text { de tratamiento ofrece mejores } \\
\text { resultados, QT/RT } \\
\text { concomitante o secuencial? }\end{array}$ \\
\hline 27 & $\begin{array}{l}\text { Estadio clínico } \\
\text { localmente } \\
\text { avanzado } \\
\text { (III A-III B) }\end{array}$ & $\mathrm{OT} / \mathrm{RT}$ & $\begin{array}{l}\text { Pacientes mayores de } \\
18 \text { años irresecables }\end{array}$ & $\mathrm{OT} / \mathrm{RT}$ & $\begin{array}{l}\text { ¿Cuál es el beneficio de la } \\
\text { QT/RT definitiva en el } \\
\text { tratamiento de pacientes con } \\
\text { CPCNP con estadio clínico } \\
\text { locamente avanzado } \\
\text { (III A-III B) irresecables? }\end{array}$ \\
\hline 28 & $\begin{array}{l}\text { Estadio clínico } \\
\text { localmente } \\
\text { avanzado } \\
\text { (III A-III B) }\end{array}$ & RT & $\begin{array}{l}\text { Pacientes mayores de } \\
18 \text { años irresecables }\end{array}$ & Esquemas de RT & $\begin{array}{l}\text { ¿Cuál es la dosis óptima y } \\
\text { esquema de RT en pacientes } \\
\text { con CPCNP estadio clínico } \\
\text { locamente avanzado } \\
\text { irresecables que reciben } \\
\text { tratamiento concomitante? }\end{array}$ \\
\hline 29 & $\begin{array}{l}\text { Estadio clínico } \\
\text { localmente } \\
\text { avanzado } \\
\text { (III A-III B) }\end{array}$ & RT & $\begin{array}{l}\text { Pacientes mayores de } \\
18 \text { años irresecables }\end{array}$ & RT profiláctica & $\begin{array}{l}\text { ¿Cuál es el papel de la RT } \\
\text { profiláctica a cráneo en } \\
\text { pacientes con CPCNP en estadio } \\
\text { clínico localmente avanzado? }\end{array}$ \\
\hline
\end{tabular}


Anexo B. Base de datos de preguntas clínicas (continuación)

Base de datos de preguntas clínicas

Guía de Práctica Clínica Nacional para el tratamiento del cáncer de pulmón en estadios tempranos, localmente avanzados y metastásicos

\begin{tabular}{|c|c|c|c|c|c|}
\hline & Estadio & Área evaluada & Población & Intervención & Pregunta clínica estructurada \\
\hline 30 & $\begin{array}{l}\text { Estadio clínico } \\
\text { avanzado (IV) }\end{array}$ & Cirugía & $\begin{array}{l}\text { Pacientes mayores de } \\
18 \text { años }\end{array}$ & Cirugía & $\begin{array}{l}\text { ¿Cuál es el beneficio de la } \\
\text { resección de metástasis } \\
\text { cerebrales en pacientes con } \\
\text { CPCNP con enfermedad } \\
\text { oligometastásica? }\end{array}$ \\
\hline 31 & $\begin{array}{l}\text { Estadio clínico } \\
\text { avanzado (IV) }\end{array}$ & RT & $\begin{array}{l}\text { Pacientes mayores de } \\
18 \text { años }\end{array}$ & RT & $\begin{array}{l}\text { ¿Cuál es el beneficio clínico } \\
\text { de la RT holocraneal en el } \\
\text { tratamiento de metástasis } \\
\text { cerebrales múltiples? }\end{array}$ \\
\hline 32 & $\begin{array}{l}\text { Estadio clínico } \\
\text { avanzado (IV) }\end{array}$ & RT & $\begin{array}{l}\text { Pacientes mayores de } \\
18 \text { años }\end{array}$ & RT & $\begin{array}{l}\text { ¿Cuál es el beneficio clínico } \\
\text { de la RT adyuvante posterior a } \\
\text { la resección de metástasis } \\
\text { cerebrales? }\end{array}$ \\
\hline 33 & $\begin{array}{l}\text { Estadio clínico } \\
\text { avanzado (IV) }\end{array}$ & RT & $\begin{array}{l}\text { Pacientes mayores de } \\
18 \text { años }\end{array}$ & SBRT & $\begin{array}{l}\text { ¿Cuál es el papel de la SBRT } \\
\text { en el tratamiento de } \\
\text { metástasis cerebrales en } \\
\text { pacientes con CPCNP? }\end{array}$ \\
\hline 34 & $\begin{array}{l}\text { Estadio clínico } \\
\text { avanzado (IV) }\end{array}$ & RT & $\begin{array}{l}\text { Pacientes mayores de } \\
18 \text { años }\end{array}$ & $\mathrm{RT}$ a tumor primario & $\begin{array}{l}\text { ¿Cuál es el beneficio clínico } \\
\text { de la RT a tumor primario en } \\
\text { estadio clínico IV en pacientes } \\
\text { con CPCNP? }\end{array}$ \\
\hline 35 & $\begin{array}{l}\text { Estadio clínico } \\
\text { avanzado (IV) }\end{array}$ & RT & $\begin{array}{l}\text { Pacientes mayores de } \\
18 \text { años }\end{array}$ & RT a metástasis óseas & $\begin{array}{l}\text { ¿Cuál es el beneficio clínico } \\
\text { de la RT a metástasis óseas } \\
\text { en estadio clínico IV en } \\
\text { pacientes con CPCNP? }\end{array}$ \\
\hline 36 & $\begin{array}{l}\text { Estadio clínico } \\
\text { avanzado (IV) }\end{array}$ & Cirugía & $\begin{array}{l}\text { Pacientes mayores de } \\
18 \text { años }\end{array}$ & $\begin{array}{l}\text { Resección del tumor } \\
\text { primario }\end{array}$ & $\begin{array}{l}\text { ¿Cuál es el beneficio clínico } \\
\text { del tratamiento radical del } \\
\text { tumor primario pulmonar en } \\
\text { pacientes en estadio clínico IV } \\
\text { oligometastásicos? }\end{array}$ \\
\hline 37 & Recurrencia & Cirugía & $\begin{array}{l}\text { Pacientes mayores de } \\
18 \text { años }\end{array}$ & Cirugía & $\begin{array}{l}\text { ¿Cuál es el beneficio de la } \\
\text { cirugía en pacientes con } \\
\text { recurrencia locorregional? }\end{array}$ \\
\hline 38 & $\begin{array}{l}\text { Estadio clínico } \\
\text { avanzado (IV) }\end{array}$ & Diagnóstico & $\begin{array}{l}\text { Pacientes mayores de } \\
18 \text { años }\end{array}$ & Diagnóstico molecular & $\begin{array}{l}\text { ¿Qué pacientes son } \\
\text { candidatos para realizar } \\
\text { determinación de mutaciones } \\
\text { y cuál es el perfil básico que } \\
\text { solicitar? }\end{array}$ \\
\hline 39 & $\begin{array}{l}\text { Estadio clínico } \\
\text { avanzado (IV) }\end{array}$ & QT & $\begin{array}{l}\text { Pacientes mayores de } \\
18 \text { años sin mutaciones } \\
\text { sensibles a terapia } \\
\text { blanco detectadas }\end{array}$ & QT paliativa & $\begin{array}{l}\text { ¿Existe alguna diferencia entre } \\
\text { esquemas con monoterapia, } \\
\text { doblete o triplete? }\end{array}$ \\
\hline 40 & $\begin{array}{l}\text { Estadio clínico } \\
\text { avanzado (IV) }\end{array}$ & QT & $\begin{array}{l}\text { Pacientes mayores de } \\
18 \text { años }\end{array}$ & QT paliativa & $\begin{array}{l}\text { ¿Los esquemas basados en } \\
\text { carboplatino son tan efectivos } \\
\text { como con cisplatino? }\end{array}$ \\
\hline 41 & $\begin{array}{l}\text { Estadio clínico } \\
\text { avanzado (IV) }\end{array}$ & Quimioterapia & $\begin{array}{l}\text { Pacientes mayores de } \\
18 \text { años sin mutaciones } \\
\text { sensibles a terapia } \\
\text { blanco detectadas }\end{array}$ & Quimioterapia paliativa & $\begin{array}{l}\text { ¿Cuál es el mejor esquema de } \\
\text { QT en primera línea en } \\
\text { pacientes con CPCNP en EC IV } \\
\text { de estirpe no escamoso? }\end{array}$ \\
\hline
\end{tabular}


Anexo B. Base de datos de preguntas clínicas (continuación)

\begin{tabular}{|c|c|c|c|c|c|}
\hline \multicolumn{6}{|c|}{ Base de datos de preguntas clínicas } \\
\hline \multicolumn{6}{|c|}{$\begin{array}{l}\text { Guía de Práctica Clínica Nacional para el tratamiento del cáncer de pulmón en estadios tempranos, localmente avanzados y } \\
\text { metastásicos }\end{array}$} \\
\hline & Estadio & Área evaluada & Población & Intervención & Pregunta clínica estructurada \\
\hline 42 & $\begin{array}{l}\text { Estadio clínico } \\
\text { avanzado (IV) }\end{array}$ & Quimioterapia & $\begin{array}{l}\text { Pacientes mayores de } \\
18 \text { años }\end{array}$ & Quimioterapia paliativa & $\begin{array}{l}\text { ¿Cuál es el mejor esquema de } \\
\text { QT en primera línea en } \\
\text { pacientes con CPCNP en EC IV } \\
\text { de estirpe epidermoide? }\end{array}$ \\
\hline 43 & $\begin{array}{l}\text { Estadio clínico } \\
\text { avanzado (IV) }\end{array}$ & Quimioterapia & $\begin{array}{l}\text { Pacientes mayores de } \\
18 \text { años sin mutaciones } \\
\text { sensibles a terapia } \\
\text { blanco detectadas }\end{array}$ & Quimioterapia paliativa & $\begin{array}{l}\text { ¿Cuál es el mejor esquema de } \\
\text { QT en pacientes con pobre } \\
\text { estado funcional? }\end{array}$ \\
\hline 44 & $\begin{array}{l}\text { Estadio clínico } \\
\text { avanzado (IV) }\end{array}$ & Quimioterapia & $\begin{array}{l}\text { Pacientes mayores de } \\
18 \text { años sin mutaciones } \\
\text { sensibles a terapia } \\
\text { blanco detectadas }\end{array}$ & Quimioterapia paliativa & $\begin{array}{l}\text { ¿Cuál es el mejor esquema de } \\
\text { QT en pacientes con edad } \\
\text { avanzada (> } 70 \text { años)? }\end{array}$ \\
\hline 45 & $\begin{array}{l}\text { Estadio clínico } \\
\text { avanzado (IV) }\end{array}$ & Quimioterapia & $\begin{array}{l}\text { Pacientes mayores de } \\
18 \text { años sin mutaciones } \\
\text { sensibles a terapia } \\
\text { blanco detectadas }\end{array}$ & Quimioterapia paliativa & $\begin{array}{l}\text { ¿Cuál es la duración óptima } \\
\text { del tratamiento (sin } \\
\text { mantenimiento) con } \mathrm{QT} \text { en } \\
\text { primera línea en pacientes con } \\
\text { CPCNP en EC IV? }\end{array}$ \\
\hline 46 & $\begin{array}{l}\text { Estadio clínico } \\
\text { avanzado (IV) }\end{array}$ & Quimioterapia & $\begin{array}{l}\text { Pacientes mayores de } \\
18 \text { años sin mutaciones } \\
\text { sensibles a terapia } \\
\text { blanco detectadas }\end{array}$ & $\begin{array}{l}\text { Terapia blanco } \\
\text { Paliativa }\end{array}$ & $\begin{array}{l}\text { ¿Qué beneficio tiene la } \\
\text { combinación de } 0 T \text { más } \\
\text { anti-EGFR en esquemas de } \\
\text { primera línea en pacientes con } \\
\text { CPCNP con EC IV? }\end{array}$ \\
\hline 47 & $\begin{array}{l}\text { Estadio clínico } \\
\text { avanzado (IV) }\end{array}$ & Quimioterapia & $\begin{array}{l}\text { Pacientes mayores de } \\
18 \text { años sin mutaciones } \\
\text { sensibles a terapia } \\
\text { blanco detectadas }\end{array}$ & $\begin{array}{l}\text { Terapia blanco } \\
\text { Paliativa }\end{array}$ & $\begin{array}{l}\text { ¿Qué beneficio tiene la } \\
\text { combinación de } 0 T \text { más } \\
\text { bevacizumab en esquemas de } \\
\text { primera línea en pacientes con } \\
\text { CPCNP con EC IV? }\end{array}$ \\
\hline 48 & $\begin{array}{l}\text { Estadio clínico } \\
\text { avanzado (IV) }\end{array}$ & Quimioterapia & $\begin{array}{l}\text { Pacientes mayores de } \\
18 \text { años sin mutaciones } \\
\text { sensibles a terapia } \\
\text { blanco detectadas }\end{array}$ & Mantenimiento & $\begin{array}{l}\text { ¿Qué beneficio tiene la terapia } \\
\text { de mantenimiento o el switch } \\
\text { en pacientes que tuvieron } \\
\text { respuesta al tratamiento } \\
\text { inicial? }\end{array}$ \\
\hline 49 & $\begin{array}{l}\text { Estadio clínico } \\
\text { avanzado (IV) }\end{array}$ & Quimioterapia & $\begin{array}{l}\text { Pacientes mayores de } \\
18 \text { años sin mutaciones } \\
\text { sensibles a terapia } \\
\text { blanco detectadas }\end{array}$ & $\begin{array}{l}\text { 2. }{ }^{\text {á́nea de }} \\
\text { tratamiento sistémico }\end{array}$ & $\begin{array}{l}\text { ¿Cuáles son los esquemas de } \\
\text { QT en segunda línea que han } \\
\text { demostrado beneficio clínico } \\
\text { incluyendo terapia combinada } \\
\text { con antiangiogénicos? }\end{array}$ \\
\hline 50 & $\begin{array}{l}\text { Estadio clínico } \\
\text { avanzado (IV) }\end{array}$ & Quimioterapia & $\begin{array}{l}\text { Pacientes mayores de } \\
18 \text { años sin mutaciones } \\
\text { sensibles a terapia } \\
\text { blanco detectadas }\end{array}$ & $\begin{array}{l}\text { 3. }{ }^{\text {a línea de }} \\
\text { tratamiento sistémico }\end{array}$ & $\begin{array}{l}\text { ¿Cuáles son los esquemas de } \\
\text { OT posterior a la segunda } \\
\text { línea que han demostrado } \\
\text { beneficio clínico? }\end{array}$ \\
\hline 51 & $\begin{array}{l}\text { Estadio clínico } \\
\text { avanzado (IV) }\end{array}$ & Terapia blanco & $\begin{array}{l}\text { Pacientes mayores de } \\
18 \text { años con mutaciones } \\
\text { del EGFR sensibles a } \\
\text { terapia blanco } \\
\text { detectadas }\end{array}$ & TKI & $\begin{array}{l}\text { ¿Cuáles son las opciones de } \\
\text { tratamiento en primera línea } \\
\text { con TKI en pacientes con } \\
\text { CPCNP que poseen mutación } \\
\text { de EGFR? }\end{array}$ \\
\hline 52 & $\begin{array}{l}\text { Estadio clínico } \\
\text { avanzado (IV) }\end{array}$ & Terapia blanco & $\begin{array}{l}\text { Pacientes mayores de } \\
18 \text { años con mutación } \\
\text { del EGFR de resistencia } \\
\text { a terapia blanco } \\
\text { detectadas }\end{array}$ & TKI & $\begin{array}{l}\text { ¿Qué beneficio ofrece la } \\
\text { combinación de TKI con } \\
\text { antiangiogénicos en pacientes } \\
\text { con CPCNP y mutación del } \\
\text { EGFR? }\end{array}$ \\
\hline
\end{tabular}


Anexo B. Base de datos de preguntas clínicas (continuación)

Base de datos de preguntas clínicas

Guía de Práctica Clínica Nacional para el tratamiento del cáncer de pulmón en estadios tempranos, localmente avanzados y metastásicos

\begin{tabular}{|c|c|c|c|c|c|}
\hline & Estadio & Área evaluada & Población & Intervención & Pregunta clínica estructurada \\
\hline 53 & $\begin{array}{l}\text { Estadio clínico } \\
\text { avanzado (IV) }\end{array}$ & Terapia blanco & $\begin{array}{l}\text { Pacientes mayores de } \\
18 \text { años con mutación } \\
\text { del EGFR de resistencia } \\
\text { a terapia blanco } \\
\text { detectadas }\end{array}$ & TKI & $\begin{array}{l}\text { ¿Cuáles son las opciones de } \\
\text { tratamiento en pacientes con } \\
\text { mutación de EGFR que } \\
\text { recibieron TKI y presentaron } \\
\text { progresión de la enfermedad y } \\
\text { se detectó mutación de } \\
\text { resistencia (T790M)? }\end{array}$ \\
\hline 54 & $\begin{array}{l}\text { Estadio clínico } \\
\text { avanzado (IV) }\end{array}$ & Terapia blanco & $\begin{array}{l}\text { Pacientes mayores de } \\
18 \text { años con mutación } \\
\text { del EGFR de resistencia } \\
\text { no detectada }\end{array}$ & Quimioterapia & $\begin{array}{l}\text { ¿Cuáles son las opciones de } \\
\text { tratamiento en pacientes con } \\
\text { mutación de EGFR que } \\
\text { recibieron TKI y presentaron } \\
\text { progresión de la enfermedad y } \\
\text { NO se detectó mutación de } \\
\text { resistencia? }\end{array}$ \\
\hline 55 & $\begin{array}{l}\text { Estadio clínico } \\
\text { avanzado (IV) }\end{array}$ & Terapia blanco & $\begin{array}{l}\text { Pacientes mayores de } \\
18 \text { años con } \\
\text { traslocación de ALK } \\
\text { detectada }\end{array}$ & TKI & $\begin{array}{l}\text { ¿Cuáles son las opciones de } \\
\text { tratamiento en primera línea } \\
\text { con TKI en pacientes con } \\
\text { CPCNP que poseen } \\
\text { traslocación de ALK? }\end{array}$ \\
\hline 56 & $\begin{array}{l}\text { Estadio clínico } \\
\text { avanzado (IV) }\end{array}$ & Terapia blanco & $\begin{array}{l}\text { Pacientes mayores de } \\
18 \text { años con } \\
\text { traslocación de ALK } \\
\text { detectada }\end{array}$ & TKI & $\begin{array}{l}\text { ¿Cuáles son las opciones de } \\
\text { tratamiento en segunda línea } \\
\text { con TKI en pacientes con } \\
\text { CPCNP que poseen traslocación } \\
\text { de ALK que progresaron a un } \\
\text { inhibidor de ALK? }\end{array}$ \\
\hline 57 & $\begin{array}{l}\text { Estadio clínico } \\
\text { avanzado (IV) }\end{array}$ & Terapia blanco & $\begin{array}{l}\text { Pacientes mayores de } \\
18 \text { años }\end{array}$ & TKI & $\begin{array}{l}\text { ¿Cuáles son las opciones de } \\
\text { tratamiento con TKI en } \\
\text { pacientes con CPCNP que } \\
\text { poseen traslocación de ROS1? }\end{array}$ \\
\hline 58 & $\begin{array}{l}\text { Estadio clínico } \\
\text { avanzado (IV) }\end{array}$ & Terapia blanco & $\begin{array}{l}\text { Pacientes mayores de } \\
18 \text { años }\end{array}$ & TKI & $\begin{array}{l}\text { ¿Cuáles son las opciones de } \\
\text { tratamiento en pacientes con } \\
\text { CPCNP que poseen otras } \\
\text { mutaciones (cMet, BRAF, HER2)? }\end{array}$ \\
\hline 59 & $\begin{array}{l}\text { Estadio clínico } \\
\text { avanzado (IV) }\end{array}$ & Inmunoterapia & $\begin{array}{l}\text { Pacientes mayores de } \\
18 \text { años sin mutaciones } \\
\text { sensibles a terapia } \\
\text { blanco detectadas }\end{array}$ & Inmunoterapia & $\begin{array}{l}\text { ¿Cuál es el beneficio de la } \\
\text { inmunoterapia como } \\
\text { monoterapia en primera línea } \\
\text { en pacientes con CPCNP? }\end{array}$ \\
\hline 60 & $\begin{array}{l}\text { Estadio clínico } \\
\text { avanzado (IV) }\end{array}$ & Inmunoterapia & $\begin{array}{l}\text { Pacientes mayores de } \\
18 \text { años sin mutaciones } \\
\text { sensibles a terapia } \\
\text { blanco detectadas }\end{array}$ & Inmunoterapia & $\begin{array}{l}\text { ¿Cuál es el beneficio de la } \\
\text { inmunoterapia en combinación } \\
\text { con QT en primera línea en } \\
\text { pacientes con CPCNP? }\end{array}$ \\
\hline 61 & $\begin{array}{l}\text { Estadio clínico } \\
\text { avanzado (IV) }\end{array}$ & Inmunoterapia & $\begin{array}{l}\text { Pacientes mayores de } \\
18 \text { años sin mutaciones } \\
\text { sensibles a terapia } \\
\text { blanco detectadas }\end{array}$ & Inmunoterapia & $\begin{array}{l}\text { ¿Cuál es el beneficio de la } \\
\text { inmunoterapia en segunda } \\
\text { línea en pacientes con } \\
\text { CPCNP? }\end{array}$ \\
\hline 62 & $\begin{array}{l}\text { Estadio clínico } \\
\text { avanzado (IV) }\end{array}$ & Inmunoterapia & $\begin{array}{l}\text { Pacientes mayores de } \\
18 \text { años de alto riesgo } \\
\text { para desarrollar } \\
\text { metástasis cerebrales }\end{array}$ & Inmunoterapia & $\begin{array}{l}\text { ¿Cuál es el beneficio del uso } \\
\text { de nivolumab más ipilimumab } \\
\text { en primera línea de } \\
\text { tratamiento en pacientes con } \\
\text { CPCNP? }\end{array}$ \\
\hline
\end{tabular}

CP: cáncer de pulmón; CPCNP: cáncer de pulmón de células no pequeñas; QT: quimioterapia; RFA: ablación por radiofrecuencia; RT: radioterapia; SBRT: radioterapia estereotáctica; TKI: inhibidores de la tirosina cinasa; VATS: 
Anexo C

\section{Estrategias de búsqueda de la literatura y términos MeSH}

$\begin{array}{ll}\text { PubMed y Embase } & \\ \text { Términos MeSH } & \\ \text { Pneumonectomies } & \text { MeSH TERMS } \\ \text { Pneumonectomy } & \text { MeSH TERMS } \\ \text { Radiotherapy } & \text { MeSH TERMS } \\ \text { Immunotherapy } & \text { MeSH TERM } \\ \text { Immunotherapies } & \text { MeSH TERM } \\ \text { Tyrosine kinase inhibitors } & \text { TEXT WORD } \\ \begin{array}{l}\text { Chemotherapy } \\ \text { Adjuvant chemotherapy }\end{array} & \text { MeSH TERMS } \\ \begin{array}{l}\text { Antineoplastic chemotherapy } \\ \text { protocol }\end{array} & \text { MeSH TERMS } \\ \begin{array}{l}\text { Antineoplastic chemotherapy } \\ \text { protocols }\end{array} & \text { MeSH TERMS } \\ \text { Chemotherapies, consolidation } & \text { MeSH TERMS }\end{array}$

\section{Términos para cáncer de pulmón de células no pequeñas}

((Lung Neoplasms [mh]) OR (Lung Neoplasms) OR (Neoplasms, Lung) OR (Lung Neoplasm) OR (Neoplasm, Lung) OR (Neoplasms, Pulmonary) OR (Neoplasm, Pulmonary) OR (Pulmonary Neoplasm) OR (Pulmonary Neoplasms) OR (Lung Cancer) OR (Cancer, Lung) OR (Cancers, Lung) OR (Lung Cancers) OR (Pulmonary Cancer) OR (Cancer, Pulmonary) OR (Cancers, Pulmonary) OR (PulmonaryCancers) OR (Cancer of the Lung) OR (Cancer of Lung) OR (Carcinoma,Non-Small-Cell [mh]) OR (Carcinoma, Non-SmaII-Cell) OR (Carcinoma, Non Small Cell Lung) OR (Carcinomas, Non-Small-Cell Lung) OR (Lung Carcinoma, Non-Small-Cell) OR (Lung Carcinomas, Non-Small-Cell) OR (Non-Small-Cell Lung Carcinomas) OR (Non-SmaII-Cell Lung Carcinoma) OR (Non Small Cell Lung Carcinoma) OR (Carcinoma, Non-Small Cell Lung) OR (Non-Small Cell Lung Cancer))

\section{Algoritmos validados}

(((((Lung Neoplasms [mh]) OR (Lung Neoplasms) OR (Neoplasms, Lung) OR (Lung Neoplasm) OR (Neoplasm, Lung) OR (Neoplasms, Pulmonary) OR (Neoplasm, Pulmonary) OR (Pulmonary Neoplasm) OR (Pulmonary Neoplasms) OR (Lung Cancer) OR (Cancer, Lung) OR (Cancers, Lung) OR (Lung Cancers) OR (Pulmonary Cancer) OR (Cancer, Pulmonary) OR
(Cancers, Pulmonary) OR (PulmonaryCancers) OR (Cancer of the Lung) OR (Cancer of Lung) OR (Carcinoma,Non-Small-Cell [mh]) OR (Carcinoma, Non-Small-Cell) OR (Carcinoma, Non Small Cell Lung) OR (Carcinomas, Non-Small-Cell Lung) OR (Lung Carcinoma, Non-Small-Cell) OR (Lung Carcinomas, Non-Small-Cell) OR (Non-Small-Cell Lung Carcinomas) OR (Non-Small-Cell Lung Carcinoma) OR (Non Small Cell Lung Carcinoma) OR (Carcinoma, Non-SmaII Cell Lung) OR (Non-Small Cell Lung Cancer))))) AND

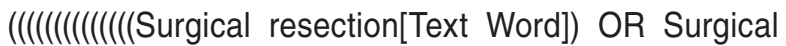
resection[Title/Abstract]) OR pneumonectomies[MeSH Terms]) OR pneumonectomy[MeSH Terms]) OR excision, lymph node[MeSH Terms]) OR excisions, lymph node[MeSH Terms]) OR Lobectom*[Text Word]) OR Wedge resection[Text Word]) OR Lymph node sampling[Text Word]) OR Limited resection[Text Word]) OR radical resection[Text Word]) OR chest wall[Text Word]) OR endoscop*[Text Word]) OR bronchoscop*[Text Word])) AND (((((“cochrane database syst rev"[Journal]) OR meta analysis[MeSH Terms]) OR meta-analysis[Publication Type]) OR systematic review[Title/Abstract]))

((()((Lung Neoplasms [mh]) OR (Lung Neoplasms) OR (Neoplasms, Lung) OR (Lung Neoplasm) OR (Neoplasm, Lung) OR (Neoplasms, Pulmonary) OR (Neoplasm, Pulmonary) OR (Pulmonary Neoplasm) OR (Pulmonary Neoplasms) OR (Lung Cancer) OR (Cancer, Lung) OR (Cancers, Lung) OR (Lung Cancers) OR (Pulmonary Cancer) OR (Cancer, Pulmonary) OR (Cancers, Pulmonary) OR (PulmonaryCancers) OR (Cancer of the Lung) OR (Cancer of Lung) OR (Carcinoma, Non-Small-Cell [mh]) OR (Carcinoma, Non-Small-Cell) OR (Carcinoma, Non Small Cell Lung) OR (Carcinomas, Non-Small-Cell Lung) OR (Lung Carcinoma, Non-Small-Cell) OR (Lung Carcinomas, Non-Small-Cell) OR (Non-Small-Cell Lung Carcinomas) OR (Non-Small-Cell Lung Carcinoma) OR (Non Small Cell Lung Carcinoma) OR (Carcinoma, Non-Small Cell Lung) OR (Non-Small Cell Lung Cancer $)))))$ AND $((((((($ radiotherap*[Text Word] $)$ OR irradiat $^{\star}[$ Text Word]) OR adjuvant radiotherapies[MeSH Terms]) OR adjuvant radiotherapy[MeSH Terms]) OR radiotherapy[MeSH Terms]) OR radiotherapy [Title/ Abstract]) OR radiotherapies[Title/Abstract])) AND (((()“cochrane database syst rev"[Journal]) OR meta analysis[MeSH Terms]) OR meta-analysis[Publication Type]) OR systematic review[Title/Abstract]))

(((((Lung Neoplasms [mh]) OR (Lung Neoplasms) OR (Neoplasms, Lung) OR (Lung Neoplasm) OR (Neoplasm, Lung) OR (Neoplasms, Pulmonary) OR (Neoplasm, Pulmonary) OR (Pulmonary Neoplasm) OR 
(Pulmonary Neoplasms) OR (Lung Cancer) OR (Cancer, Lung) OR (Cancers, Lung) OR (Lung Cancers) OR (Pulmonary Cancer) OR (Cancer, Pulmonary) OR (Cancers, Pulmonary) OR (Pulmonary Cancers) OR (Cancer of the Lung) OR (Cancer of Lung) OR (Carcinoma,Non-Small-Cell [mh]) OR (Carcinoma, Non-Small-Cell) OR (Carcinoma, Non Small Cell Lung) OR (Carcinomas, Non-Small-Cell Lung) OR (Lung Carcinoma, Non-Small-Cell) OR (Lung Carcinomas, Non-Small-CeII) OR (Non-Small-Cell Lung Carcinomas) OR (Non-Small-Cell Lung Carcinoma) OR (Non Small Cell Lung Carcinoma) OR (Carcinoma, Non-Small Cell Lung) OR (Non-Small Cell Lung Cancer))))) AND (((((“cochrane database syst rev”[Journal]) OR meta analysis[MeSH Terms]) OR meta-analysis[Publication Type]) OR systematic review[Title/Abstract]))) AND (()(()(()(()((immunotherapies[MeSH Terms]) OR Nivolumab[Text Word]) OR Nivolumab[Title/Abstract]) OR pembrolizumab[Text Word]) OR pembrolizumab[Title/ Abstract]) OR Atezolizumab[Text Word]) OR Atezolizumab[Title/Abstract]) OR immunotherapy[MeSH Terms]) OR immunotherap*[Text Word])) OR programmed cell death-ligand 1[Text Word]) OR programmed cell death-ligand 1[Title/Abstract]) OR PD-L1[Text Word]) OR PD-L1[Title/Abstract])
((((((Lung Neoplasms [mh]) OR (Lung Neoplasms) OR (Neoplasms, Lung) OR (Lung Neoplasm) OR (Neoplasm, Lung) OR (Neoplasms, Pulmonary) OR (Neoplasm, Pulmonary) OR (Pulmonary Neoplasm) OR (Pulmonary Neoplasms) OR (Lung Cancer) OR (Cancer, Lung) OR (Cancers, Lung) OR (Lung Cancers) OR (Pulmonary Cancer) OR (Cancer, Pulmonary) OR (Cancers, Pulmonary) OR (Pulmonary Cancers) OR (Cancer of the Lung) OR (Cancer of Lung) OR (Carcinoma, Non-Small-Cell [mh]) OR (Carcinoma, Non-Small-Cell) OR (Carcinoma, Non Small Cell Lung) OR (Carcinomas, Non-Small-Cell Lung) OR (Lung Carcinoma, Non-Small-Cell) OR (Lung Carcinomas, Non-Small-CeII) OR (Non-Small-Cell Lung Carcinomas) OR (Non-Small-Cell Lung Carcinoma) OR (Non Small Cell Lung Carcinoma) OR (Carcinoma, Non-Small Cell Lung) OR (Non-Small Cell Lung Cancer))))) AND ()((()(tyrosine kinase inhibit\$ or monoclonal antibod\$ or EGFR or TKI\$).tw.)) OR ((erlotinib or tarceva).af.)) OR ((gefitinib or iressa).af.)) OR ((afatinib or gilotrif).af.)) OR epidermal growth factor receptor protein tyrosine kinase[MeSH Terms])) AND ((((("cochrane database syst rev"[Journal]) OR meta analysis[MeSH Terms]) OR meta-analysis[Publication Type]) OR systematic review[Title/Abstract])) 